This item was submitted to Loughborough's Research Repository by the author.

Items in Figshare are protected by copyright, with all rights reserved, unless otherwise indicated.

\title{
CFD modeling of pharmaceuticals and CECs removal by UV/H2O2 process in helical microcapillary photoreactors and evaluation of $\mathrm{OH}$ radical rate constants
}

\section{PLEASE CITE THE PUBLISHED VERSION}

https://doi.org/10.1016/j.cej.2021.128833

\section{PUBLISHER}

Elsevier

\section{VERSION}

AM (Accepted Manuscript)

\section{PUBLISHER STATEMENT}

This paper was accepted for publication in the journal Chemical Engineering Journal and the definitive published version is available at https://doi.org/10.1016/j.cej.2021.128833.

\section{LICENCE}

CC BY-NC-ND 4.0

\section{REPOSITORY RECORD}

Peralta-Muniz-Moreira, Rodrigo, and Gianluca Li-Puma. 2021. "CFD Modeling of Pharmaceuticals and Cecs Removal by Uv/ $\mathrm{h}_{2} \mathrm{O}_{2}$ Process in Helical Microcapillary Photoreactors and Evaluation of $\mathrm{OH}$ Radical Rate Constants". Loughborough University. https://hdl.handle.net/2134/14212946.v1. 


\title{
CFD Modeling of Pharmaceuticals and CECs Removal by $\mathrm{UV} / \mathrm{H}_{2} \mathrm{O}_{2}$ Process in Helical Microcapillary Photoreactors and Evaluation of $\mathrm{OH}$ Radical Rate Constants
}

\author{
Rodrigo PERALTA MUNIZ MOREIRA* ${ }^{*}$ and Gianluca LI PUMA* \\ Environmental Nanocatalysis \& Photoreaction Engineering, Department of Chemical \\ Engineering, Loughborough University, Loughborough, United Kingdom \\ *Corresponding authors: Rodrigo PERALTA MUNIZ MOREIRA (r.peralta- \\ munizmoreira@lboro.ac.uk) and Gianluca LI PUMA (g.lipuma@lboro.ac.uk)
}




\begin{abstract}
Process intensification by tailored secondary flow in helical microcapillary film (MCF) photoreactors was unveiled by computational fluid dynamics, and it was revealed for the removal of six common contaminants of emerging concern CECs (the antiviral Acyclovir, the antiretrovirals Stavudine and Zidovudine, and the biocidal antifungal agents Methylisothiazolinone, Benzisothiazolinone and Isoxazole) in water by UV hydrogen peroxide. The MCF photoreactors consisted of fluoropolymer films containing 10 microchannels with diameter varying from 100 to $1000 \mu \mathrm{m}$ coiled around a UVC lamp. In contrast to a MCF with straight channels, mixing intensification by secondary flow (Dean vortices) caused by the helical shape of the microcapillary, strongly enhanced the radial fluid mixing, further supplementing the transport of the reacting species by Taylor-Aris dispersion. The intensity of the Dean vortices formed was correlated to the Dean $(D e)$ and Schmidt $(S c)$ numbers through a new correlation for the radial Peclet, which established that these become significant when $D e^{1.94} S c>67$. Thus, the second-order reaction rate constant of the six pharmaceuticals with $\mathrm{OH}^{\cdot}$ radicals $\left(k_{O H}\right)$ determined in a helical MCF photoreactor increased (4.4\% up to $37.9 \%$ ) in comparison to those determined assuming a MCF photoreactor with plug flow. In addition, the helical shape of the MCF significantly diminished mass transfer limitations and decreased the CECs Electrical Energy per Order Reduction $\left(E_{E O}\right)$, paving the way for scaling-up of helical microcapillary photoreactor technology. This study shows how micromixing can be successfully exploited to design more efficient microcapillary photoreactors.
\end{abstract}

Keywords: Advanced oxidation process, Water treatment, Photochemical peroxidation, Contaminants of Emerging Concern, Microreactor, Modelling. 


\section{Introduction}

Advanced oxidation processes (AOPs) are rapidly emerging as advanced water treatment methods to remove pollutants and contaminants of emerging concern (CECs) from contaminated streams or effluents $[1,2,3]$. The CECs, including pharmaceuticals and personal care products, can be detected in the effluents of wastewater treatment plants (WWTPs) and in other industrial and domestic wastewaters at concentrations levels ranging from tens to thousands of $\mathrm{ng} / \mathrm{L}$, and these constitute a potential threat to both the ecosystem and human health $[4,5]$. Certainly, process intensification plays a key role in increasing the penetration of AOPs for the removal of CECs from WWTP effluents, and in other emerging areas, such as green chemicals synthesis, chemical transformations and diagnostics. It relies on the development of more efficient reactors, more efficient light sources and reactor operating conditions, and in integrating these elements together.

In this context, microreactors have attracted significant interest for process intensification in the last decade due to fast development and application of microfluidics devices $[6,7]$. The main advantages of microreactors are short reaction or space time, high yield and selectivity, reduced consumption of reagents and solvents, higher surface-to-volume ratio, intensification of heat and mass transfer and increased safety $[8,9,10]$. Advances in homogeneous [11] and heterogeneous [12] photochemical transformations of organic and inorganic species have highlighted the potential of miniaturized photoreactors as cleaner and efficient platforms for chemical reactions $[13,14,15,16]$. Microreactors also offer a controlled environment for determinations of intrinsic kinetics by the lab-in-a-chip concept [17]. However, in scaled-up microreactor systems (e.g., by numbering up the microchannels) it is critical to ensure a uniform distribution of radiation to all units of the microreactors [18].

The microcapillary film (MCF) photoreactor technology has recently been proposed as a safe, ultrafast and efficient method to determine photo-transformation reaction kinetics and 
transformation products of micropollutants and biological species by photochemical AOPs processes such as by $\mathrm{UV}_{254}$ and $\mathrm{UV}_{254} / \mathrm{H}_{2} \mathrm{O}_{2}$ [19]. Unlike traditional microreactors, the MCF high flexibility allows it to be coiled around a cylindrical UV lamp, ensuring uniform irradiation of the fluid with straight rays, in a fully transparent and optical thin medium [20, 19]. The use of MCF for ultrarapid photochemical peroxidation investigations was demonstrated by comparisons with a radically different cylindrical batch reactor [21]. Recently, the MCF photoreactor method has been used to investigate the photo-transformation of several CECs, including the determination of the quantum yield and second-order rate constant of the reaction of the micropollutants with $\mathrm{OH}^{*}$ radicals. Herpes HSV-1 virus inactivation [19], the transformation product of cocaine (benzoylecgonine [21]), the antiviral and antiretrovirals (acyclovir [22], stavudine and zidovudine [23]), and the biocidal antifungal agents (methylisothiazolinone, benzisothiazolinone and isoxazole [24]) are some CECs that have been investigated.

Indeed, precise second-order kinetics constants should be employed when evaluating the application of $\mathrm{UV} / \mathrm{H}_{2} \mathrm{O}_{2}$ for the degradation of CECs. However, the determined rate constants in the above-mentioned studies may contain some uncertainties caused by mass transfer limitations, since the fluid-dynamics was modeled as plug flow despite the flow regime in the MCF was well within the laminar regime. In a Residence Time Distribution (RTD) study of an unreactive tracer in the MCF, an apparent plug flow with axial dispersion was observed [20]. One possible reason for the apparent plug flow is the strong radial diffusional gradients of the species due to the small microchannel diameter. Another possible reason, unreported in previous studies, can be the existence of a secondary flow, known as Dean vortices [25]. Although the flow is unidirectional for $D e<2$ (conditions studied in $[19,21,22,23,24]$ ), the secondary flow generated in the MCF photoreactors might still contribute to mixing intensification [25, 26, 27, 28]. 
Computational fluid dynamics (CFD) has emerged as an attractive tool to study the process intensification by means of Dean vortices reacting systems. The impact of Dean vortices in microsystems has been studied by CFD to evaluate the pressure drop [29, 30], the heat transfer $[31,32]$ and to predict the mixing intensification in coiled flow inverters $[33,34$, $35,36]$ and helical micromixers [37, 38]. However, fluid dynamics simulations in high aspect ratio coiled microreactors (length to diameter ratio) remain computationally challenging, due to the mesh refinement needed to capture the geometric curvatures of the reactor. For instance, 2 million cells were required to predict the mixing in a helical tube with only 5 turns [37] for a low curvature ratio of the coil $(\sim 10)$. In contrast, the MCF studied in $[19,21,22,23,24]$ displayed a curvature ratio $\sim 80$ and more than 30 turns around the UV lamp. As an alternative to the CFD model, analytical approximations of flow field can be used, however, these might lead to significant discrepancies from experimental data $[39,40,41]$, and require the solution the three-dimensional mass transport equation.

In this study, CFD was used to evaluate the impact of the secondary flow (Dean vortices) on the photochemical transformation of CECs by the $\mathrm{UV}_{254} / \mathrm{H}_{2} \mathrm{O}_{2}$ process in $\mathrm{MCF}$ photoreactors. Firstly, a novel methodology to solve high aspect ratio coiled microcapillaries with low computational cost was proposed and validated by comparisons with experimental results of residence time distribution (RTD). Then, for the first time, the secondary flow and diffusion rates in the MCF photoreactors were analyzed to unveil the conditions that determine the inception of secondary flow and its impact on process intensification. With the validated model, the CFD model was applied to predict more accurately the second-order kinetics constants of hydroxyl radical attack to the micropollutant $\left(k_{O H}\right)$ of the $\mathrm{UV} / \mathrm{H}_{2} \mathrm{O}_{2}$ degradation process of acyclovir, a very common antiviral used to treat herpes infections, the antiretrovirals stavudine and zidovudine used against HIV, and the biocidal antifungal agents methylisothiazolinone, benzisothiazolinone and isoxazole widely used in consumer products 
such as toiletries, cosmetics and cleaning products. Finally, the impact of secondary flow was determined for different microcapillary diameters, Reynolds and Dean numbers, and the Electrical Energy per Order Reduction $\left(\mathrm{E}_{\mathrm{EO}}\right)$ was calculated to disclose the conditions for the optimal design of MCF photoreactors.

\section{Methodology}

\subsection{Reactor geometry, operating conditions and experimental data}

The microcapillary array photoreactor consisted of a flat surface fluoropolymer film containing ten $\mathrm{UV}_{254}$ transparent microcapillaries with length $(L)$ of $2.2 \mathrm{~m}$ and mean hydraulic diameter $\left(D_{\text {cap }}\right)$ of $195 \mu \mathrm{m}$. The film was coiled around a UV monochromatic (254 nm) lamp (Germicidal G8T5) in the region with uniform emission, thus, producing a helical geometry of the photoreactor. Fig. 1 shows a photograph of the microcapillary array [20].

In this study, experiments from literature were used to validate the CFD model. These were carried out to determine the Residence Time Distribution (RTD) [20] and photochemical peroxidation degradation of acyclovir (ACY) [22], stavudine (STV) and zidovudine (ZDV) [23], and methylisothiazolinone (MIT), benzisothiazolinone (BIT) and isoxazole (ISOX) [24]. A brief description of the experimental setup is shown in this article, and more details can be found elsewhere $[20,19,22,23,24]$.

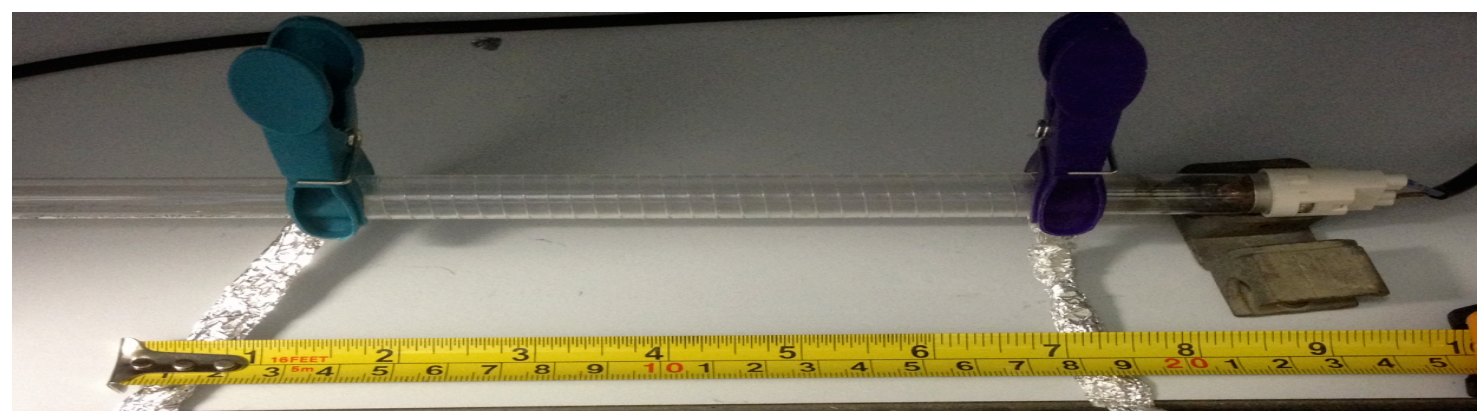

Fig. 1. The MCF coiled on an $\mathrm{UV}_{254}$ lamp. 
The RTD was determined experimentally using two pumps connected to a multi-inlet valve to switch the inlet from water to a Blue Dextran 70 (TdB Consultancy AB, Sweden) dissolved in water (1000 ppm), producing a step change in concentration that was monitored until the outlet reached a stationary state. The flow rate in the microcapillary array ranged from $6.0 \cdot 10^{-4}$ to $10.0 \cdot 10^{-4} \mathrm{~L} / \mathrm{min}\left(6.0 \cdot 10^{-5}\right.$ to $10.0 \cdot 10^{-5} \mathrm{~L} / \mathrm{min}$ per microcapillary $)$, i.e., the $R e$ ranged from 6.5 to 10.9 .

The photochemical peroxidation of ACY, STV, ZDV, MIT, BIT and ISOX were experimentally studied at a constant flow rate $\left(6.0 \cdot 10^{-5} \mathrm{~L} / \mathrm{min}\right.$ per microcapillary) in ultrapure MilliQ water varying the concentration of $\mathrm{H}_{2} \mathrm{O}_{2}(0.7-10 \mathrm{mM})$, the concentration of the micropollutant (30-90 $\mu \mathrm{M})$, the lamp power (4.5-8 W) and the $\mathrm{pH}$ (4 to 8). The concentrations leaving the microcapillary were collected into vials at the outlet of the reactor and analyzed using a high-performance liquid chromatograph (HPLC). Then, these measurements were used to estimate the kinetic constant of hydroxyl radical attack to the micropollutant. Microcapillaries with different lengths were used to compute the degradation rate under different reaction space times. The physico-chemical properties and operating conditions adopted are summarized in Table 1, and the mass diffusion coefficients of the chemical species are shown in Table S1 in Supplementary Information (SI). 
Table 1. Physico-chemical properties and operating conditions of experimental measurements.

\begin{tabular}{|c|c|}
\hline \multicolumn{2}{|l|}{ Operating conditions ${ }^{\mathrm{a}}$} \\
\hline Flow rate $(Q)[\mathrm{L} / \mathrm{min}]$ & $6.0 \cdot 10^{-4}$ and $10.0 \cdot 10^{-4}$ \\
\hline Ambient temperature $\left[{ }^{\circ} \mathrm{C}\right]$ & 25 \\
\hline Microcapillary diameter $\left(D_{c a p}\right)[\mu \mathrm{m}]$ & 195 \\
\hline Reynolds number $(R e)$ & 6.5 and 10.9 \\
\hline Dean number $(D e)$ & 0.7 and 1.2 \\
\hline Microcapillary length $(L)[\mathrm{mm}]$ & 2200 \\
\hline Number of microcapillaries per array & 10 \\
\hline Lamp power $(P)[\mathrm{W}]$ & 4.5 and 8 \\
\hline Lamp diameter $\left(D_{L}\right)[\mathrm{mm}]$ & 16 \\
\hline Photon flux per unit volume emitted $\left(P_{0}\right)[\mathrm{ein} /(\mathrm{s} . \mathrm{L})]$ & $1.27 \cdot 10^{-2}$ and $1.92 \cdot 10^{-2}$ \\
\hline Average optical path length $\left(l_{c a p}\right)[\mu \mathrm{m}]$ & 154 \\
\hline \multicolumn{2}{|l|}{ Physico-chemical properties ${ }^{b}$} \\
\hline Water density $(\rho)\left[\mathrm{kg} / \mathrm{m}^{3}\right]$ & 998.2 \\
\hline Water viscosity $(\mu)[\mathrm{cP}]$ & 1 \\
\hline
\end{tabular}

Experimentally, the lamp irradiance was varied by changing the lamp nominal power from 4.5 $\mathrm{W}$ to $8.0 \mathrm{~W}$, and the photon flux per unit volume emitted $\left(P_{0}\right)$ for each lamp power was determined using $\mathrm{H}_{2} \mathrm{O}_{2}$ actinometry [20]. The mean optical path length $\left(l_{c a p}\right)$, i.e., the mean perpendicular distance from the lamp bulb to microcapillaries external wall, was estimated assuming that the UV radiation was perpendicular to the surface of the bulb and crossed the microcapillary external wall and the reacting solution without any deviation of path length. This assumption is valid due to the flat surface of light entrance wall of the 
microcapillary combined with excellent optical transparency and low refractive index [19]. The $l_{\text {cap }}$ for the circular section of the microreactor was calculated from the ratio between the hydraulic area $(S)$ and the diameter of the microcapillary, as follows:

$$
l_{\text {cap }}=\frac{S}{D_{c a p}}=\frac{\pi D_{c a p}}{4}
$$

In addition to the experimental conditions described in Table 1, CFD simulations were carried out to study the effect of the secondary flow under different values of Dean number (Eq. (3)). The Reynolds number (Eq. (2)) ranged from 1 to 80, the microcapillary diameter $\left(D_{\text {cap }}\right)$ ranged from 100 to $1000 \mu \mathrm{m}$ and the lamp diameter $\left(D_{L}\right)$ varied between 16 and $32 \mathrm{~mm}$. The Dean number $(D e)$ ranged from 0.1 to 20 . For this range of $D e$, the secondary flow does not affect the axial velocity profile and neither the pressure drop in the coiled MCF compared with straight microcapillaries [26]. The Reynolds $(R e)$ and Dean $(D e)$ number are defined as follows:

$$
\begin{aligned}
& R e=\frac{\rho u D_{c a p}}{\mu} \\
& D e=\operatorname{Re} \sqrt{\frac{D_{c a p}}{D_{L}}}
\end{aligned}
$$

Note that analyses with different microcapillary diameter required the recalculation of the optical path length and the photon flux per unit volume emitted by the UV lamp $\left(P_{0}\right)$. While the $l_{\text {cap }}$ was calculated according to the Eq. (1), $P_{o}$ was calculated by assuming a constant photon flux [ein $\mathrm{m}^{-2} \mathrm{~s}^{-1}$ ] in the microcapillary $\left(P_{0} l_{\text {cap }}\right)$. This assumption is described in the Supplementary Information (SI) (Estimation of photon flux per unit volume). 


\subsection{Governing equations}

The flow was modeled as laminar $(R e \leq 80)$. The mass and momentum conservation equations for incompressible flows (neglecting gravitational force) in cartesian index notation are:

$$
\begin{aligned}
& \frac{\partial \rho}{\partial t}+\frac{\partial}{\partial x_{i}}\left(\rho u_{i}\right)=0 \\
& \frac{\partial}{\partial t}\left(\rho u_{i}\right)+\frac{\partial}{\partial x_{j}}\left(\rho u_{j} u_{i}\right)=-\frac{\partial p}{\partial x_{i}}+\frac{\partial}{\partial x_{j}}\left(\mu \frac{\partial u_{i}}{\partial x_{j}}\right)
\end{aligned}
$$

where $u_{i}$ and $p$ are the velocity and the pressure, $\rho$ is the fluid density and $\mu$ is the fluid dynamic viscosity.

The flow solution was coupled to the mass conservation equations of unreactive and reactive chemical species. The mass conservation of the unreactive tracer (Blue Dextran 70) was used to determine the RTD, while mass conservations of the reacting species (micropollutant and $\mathrm{H}_{2} \mathrm{O}_{2}$ ) were used to determine the removal rates. The specie mass conservation, of all $k^{\text {th }}$ chemical species for laminar flows are given by Eq. (6), except for the mass conservation of the $\mathrm{H}_{2} \mathrm{O}$, the inert and the most abundant chemical specie, that was solved by Eq. (7):

$$
\begin{aligned}
& \frac{\partial}{\partial t}\left(\rho Y_{k}\right)+\frac{\partial}{\partial x_{j}}\left(\rho u_{j} Y_{k}\right)=\rho D_{k, m} \frac{\partial^{2} Y_{k}}{\partial x_{j}^{2}}+M_{w, k} r_{k} \\
& Y_{N}=1-\sum_{k}^{N_{S}-1} Y_{k}
\end{aligned}
$$

where $Y_{k}$ is the mass fraction of the $k$ species, $D_{k, m}$ is the mass diffusivity of species $k$ in the mixture and $M_{w, k}$ is the molecular weight of specie $k$ and $r_{k}$ is the net reaction rate for reactant $k\left[\mathrm{kmol} \mathrm{m}{ }^{-3} \mathrm{~s}^{-1}\right]$. The kinetic mechanism of the $\mathrm{UV}_{254} / \mathrm{H}_{2} \mathrm{O}_{2}$ process is shown in Table 2 . 


\subsection{Residence Time Distribution in the microcapillary reactor}

The RTD was numerically evaluated by a pulse-response analysis and compared with the experimental results. Eq. (6) was solved in transient mode for a non-reacting numerical tracer $\left(r_{k}=0 \mathrm{kmol} \mathrm{m}^{-3} \mathrm{~s}^{-1}\right)$ injected as a pulse function at the entrance of the microcapillary. The dynamic concentration of the tracer was measured at cross sectional planes along the length of the microcapillary. Then, the dimensionless form of the RTD curve $(\mathrm{E}(\theta))$ and the cumulative RTD curve $(F(\theta))$ were determined through Eqs. (8)-(11) [43]:

$$
\begin{aligned}
& \tau=\frac{\int_{0}^{\infty} t C(t) d t}{\int_{0}^{\infty} C(t) d t} \\
& \theta=\frac{t}{\tau} \\
& E(\theta)=\tau \frac{C(t)}{\int_{0}^{\infty} C(t) d t} \\
& F(\theta)=\int_{0}^{\infty} E(\theta) d t
\end{aligned}
$$

where $\tau$ is the mean residence time (or space time) and $\theta$ is the dimensionless time. $C(t)$ is the mass-flow average concentration of the tracer at time $t$ calculated at a measurement plane with cross-section area $A$, given by:

$$
\mathrm{C}(\mathrm{t})=\frac{\int_{A} \rho u_{z} C(t) d A}{\int_{A} \rho u_{z} d A}
$$

The axial dispersion was quantitatively measured by fitting the obtained RTD to the Dispersion Model [43]. The Dispersion Model is used for a plug flow RTD with axial dispersion, in which the magnitude of axial dispersion is measured by the axial dispersion coefficient $\left(N_{D}\right)$ :

$$
N_{D}=\frac{D_{e f f}}{u_{z} L}
$$


where $D_{e f f}$ is the effective axial dispersion coefficient, $u_{z}$ is the mean axial velocity and $L$ is the microcapillary length.

Negligible dispersion is approached when $N_{D} \rightarrow 0$, hence (plug flow), while a large dispersion is obtained when $N_{D} \rightarrow \infty$ (mixed flow). The $N_{D}$ was determined by the $\tau$ and the variance of $\tau\left(\sigma_{\tau}^{2}\right)$ of the RTD distribution, using Eqs. (14)-(16).

$$
\begin{aligned}
& \frac{\sigma_{\tau}^{2}}{\tau^{2}}=2 N_{D}-2 N_{D}^{2} \cdot\left(1-e^{-\frac{1}{N_{D}}}\right), \text { for } N_{D}>0.01 \\
& \frac{\sigma_{\tau}^{2}}{\tau^{2}}=2 N_{D}, \text { for } N_{D}<0.01 \\
& {\sigma_{\tau}^{2}}^{2}=\frac{\int_{0}^{\infty}(t-\tau)^{2} C(t) d t}{\int_{0}^{\infty} C(t) d t}
\end{aligned}
$$

\subsection{Kinetic mechanism of the removal of micropollutants by the $\mathrm{UV} / \mathrm{H}_{2} \mathrm{O}_{2}$ process}

Table 2 presents the kinetic mechanism of the removal of micropollutants (MP) by the $\mathrm{UV}_{254} / \mathrm{H}_{2} \mathrm{O}_{2}$ process $[22,23,24]$ in the absence of scavenging species. The modeling of the $\mathrm{UV} / \mathrm{H}_{2} \mathrm{O}_{2}$ process by the mechanism shown was previously validated in $[21,44]$. The quantum yields $(\phi)$ and decadic molar absorption coefficients $\left(\epsilon^{254}\right)$ at $\mathrm{UV}_{254}$ for the water contaminants studied are shown in Table S2.

Table 2. Kinetic mechanism of micropollutants (MP) removal by $\mathrm{UV}_{254} / \mathrm{H}_{2} \mathrm{O}_{2}$ process.

\begin{tabular}{lll}
\hline Reaction & Kinetics constants & Reference \\
\hline$M P \stackrel{h}{\rightarrow}$ TPS & $\phi_{M P}$ & Table S2 \\
& $\epsilon_{M P}^{254}$ & \\
$\mathrm{H}_{2} \mathrm{O}_{2} \stackrel{h}{\rightarrow} 2 \mathrm{OH}^{\bullet}$ & $\phi_{\mathrm{H}_{2} \mathrm{O}_{2}}=0.55 \mathrm{~mol} / \mathrm{ein}$ & {$[45]$} \\
& $\epsilon_{\mathrm{H}_{2} \mathrm{O}_{2}}^{254}=18.6 \mathrm{M}^{-1} \mathrm{~cm}^{-1}$ \\
& $k_{h}=2.7 \cdot 10^{7} \mathrm{M}^{-1} \mathrm{~s}^{-1}$ &
\end{tabular}




\begin{tabular}{lll}
\hline $\mathrm{MP}+\mathrm{OH} \cdot \stackrel{k_{\mathrm{OH} / \mathrm{MP}}}{\longrightarrow} \mathrm{TPS}$ & $k_{\mathrm{OH} / \mathrm{MP}}$ & $\begin{array}{l}\text { Estimated } \\
\text { in this } \\
\text { study }\end{array}$ \\
$\mathrm{TPS}+\mathrm{OH} \cdot \stackrel{k_{\mathrm{OH} / \mathrm{TP}}^{\longrightarrow}}{\longrightarrow} \mathrm{TP}$ & $k_{O H / T P}$ & $\begin{array}{l}\text { Estimated } \\
\text { in this } \\
\text { study }\end{array}$ \\
$2 \mathrm{HO}_{2} \stackrel{k_{t}}{\rightarrow} \mathrm{H}_{2} \mathrm{O}_{2}+\mathrm{O}_{2}$ & $k_{t}=8.3 \cdot 10^{5} \mathrm{M}^{-1} \mathrm{~s}^{-1}$ & [47] \\
\hline
\end{tabular}

The net rate of reaction for each reacting species are:

$$
\begin{aligned}
& r_{O H^{\bullet}}=2 F_{H_{2} O_{2}}-\left[\mathrm{OH}^{\bullet}\right]\left(k_{h}\left[\mathrm{H}_{2} \mathrm{O}_{2}\right]+k_{O H / M P}[\mathrm{MP}]+k_{O H / T P}[\mathrm{TPS}]\right) \\
& r_{\mathrm{HO}_{2}} \cdot=k_{h}\left[\mathrm{OH}^{\bullet}\right]\left[\mathrm{H}_{2} \mathrm{O}_{2}\right]-2 k_{t}\left[\mathrm{HO}_{2}^{\bullet}\right]^{2} \\
& r_{\mathrm{H}_{2} \mathrm{O}_{2}}=-F_{\mathrm{H}_{2} \mathrm{O}_{2}}-k_{H}\left[\mathrm{H}_{2} \mathrm{O}_{2}\right]\left[\mathrm{OH}^{\bullet}\right]+k_{t}\left[\mathrm{HO}_{2}^{\bullet}\right]\left[\mathrm{HO}_{2}^{\bullet}\right] \\
& r_{M P}=-F_{M P}-k_{O H / M P}[\mathrm{MP}]\left[\mathrm{OH}^{\bullet}\right] \\
& F_{\mathrm{H}_{2} \mathrm{O}_{2}}=\phi_{\mathrm{H}_{2} \mathrm{O}_{2}} P_{O}\left(1-\exp \left(-\ln (10) l_{c a p}\left(\epsilon_{254}^{M P}[\mathrm{MP}]+\epsilon_{254}^{\mathrm{H}_{2} \mathrm{O}_{2}}\left[\mathrm{H}_{2} \mathrm{O}_{2}\right]\right)\right)\right) f_{\mathrm{H}_{2} \mathrm{O}_{2}} \\
& F_{M P}=\phi_{A C Y} P_{O}\left(1-\exp \left(-\ln (10) l_{c a p}\left(\epsilon_{254}^{M P}[M P]+\epsilon_{254}^{H_{2} O_{2}}\left[\mathrm{H}_{2} \mathrm{O}_{2}\right]\right)\right)\right) f_{M P}
\end{aligned}
$$

where $f_{\mathrm{H}_{2} \mathrm{O}_{2}}$ and $f_{M P}$ are the fraction of photons absorbed by the hydrogen peroxide and the micropollutant, respectively, calculated by:

$$
\begin{gathered}
f_{\mathrm{H}_{2} \mathrm{O}_{2}}=\frac{\epsilon_{254}^{\mathrm{H}_{2} \mathrm{O}_{2}}\left[\mathrm{H}_{2} \mathrm{O}_{2}\right]}{\epsilon_{254}^{M P}[M P]+\epsilon_{254}^{\mathrm{H}_{2} \mathrm{O}_{2}}\left[\mathrm{H}_{2} \mathrm{O}_{2}\right]} \\
f_{M P}=\frac{\epsilon_{254}^{M P}[M P]}{\epsilon_{254}^{M P}[M P]+\epsilon_{254}^{\mathrm{H}_{2} \mathrm{O}_{2}}\left[\mathrm{H}_{2} \mathrm{O}_{2}\right]}
\end{gathered}
$$

Assuming a rapidly steady state kinetics for the radicals species (Eq. (25)-(26)), the net rates of $\mathrm{MP}$ and $\mathrm{H}_{2} \mathrm{O}_{2}$ are given by Eq. (27)-(28).

$$
\left[\mathrm{OH}^{\bullet}\right]_{S S}=\frac{2 F_{\mathrm{H}_{2} \mathrm{O}_{2}}}{k_{h}\left[\mathrm{H}_{2} \mathrm{O}_{2}\right]+k_{O H / M P}[\mathrm{MP}]+k_{O H / T P}[T P S]}
$$




$$
\begin{aligned}
& {\left[\mathrm{HO}_{2}\right]_{S S}{ }^{2}=\frac{k_{h} F_{\mathrm{H}_{2} \mathrm{O}_{2}}\left[\mathrm{H}_{2} \mathrm{O}_{2}\right]}{k_{t}\left(k_{h}\left[\mathrm{H}_{2} \mathrm{O}_{2}\right]+k_{O H / M P}[\mathrm{MP}]+k_{O H / T P}[\mathrm{TPS}]\right)}} \\
& r_{\mathrm{H}_{2} \mathrm{O}_{2}}=-F_{\mathrm{H}_{2} \mathrm{O}_{2}}-\frac{k_{h}\left[\mathrm{H}_{2} \mathrm{O}_{2}\right] F_{\mathrm{H}_{2} \mathrm{O}_{2}}}{k_{h}\left[\mathrm{H}_{2} \mathrm{O}_{2}\right]+k_{O H / M P}[M P]+k_{O H / T P}[T P S]} \\
& r_{M P}=-F_{M P}-\frac{2 k_{O H / M P}[M P] F_{\mathrm{H}_{2} \mathrm{O}_{2}}}{k_{h}\left[\mathrm{H}_{2} \mathrm{O}_{2}\right]+k_{O H / M P}[M P]+k_{O H / T P}[T P S]}
\end{aligned}
$$

where the concentration of intermediate photo-transformation products ([TPs]) is given by:

$$
[T P s]=[M P]_{0}-[M P]
$$

Lastly, the kinetics constants $k_{O H / M P}$ and $k_{O H / T P}$ were assumed to be equal, and only the kinetic constant of hydroxyl radical attack to the micropollutant/transformation by-products $\left(k_{O H}\right)$ was determined for each micropollutant. Thermal effects in the MCF were neglected due to the short space time. Experimentally, the changes in temperature were insignificant. The concentrations of MP and $\mathrm{H}_{2} \mathrm{O}_{2}$ were measured at different cross-sectional planes along the microcapillary length, and these were computed using mass-flow average equations (Eq. (12)).

\subsection{Radiation Field}

The radiation field inside the microcapillary was not solved due to the very low optical thickness (typically 0.01 with the highest condition approaching 0.1 ) which produced a gradientless transversal irradiance profile. MCFs can handle fluids with a high degree of opacity [19], however, with water no significant gradients can be observed.

\subsection{Numerical Procedure}

The CFD software Ansys Fluent R2020 was used to solve the reacting flow in the microcapillary, and ANSYS Meshing and ICEM were used to generate the computational meshes. In addition, the optimization software Dakota 6.10 [48] was coupled to the CFD solver to perform the estimation of kinetics constants. 


\subsubsection{CFD modeling}

CFD modeling of the microcapillary photoreactor coiled around the UV lamp leads to three-dimensional geometries, without symmetries, and with tens of millions of elements, due to the large aspect ratio ( 11000 for the case in Table 1$)$ and the refinement needed to capture the helicoid curvatures. To overcome the expensive computational cost of the simulations, a numerical approach was proposed and validated in study (Fig. 2). Firstly, the fluid dynamics was solved in a toroidal section ( $3 / 4$ of a torus) of the microcapillary, to obtain the steady solution of the velocity field and pressure drop. Then, the fully developed velocity profile was exported from the toroidal geometry (verification shown in Fig. S1 (SI) in Supplementary Information (SI)) and imported in a CFD simulation using a straight microcapillary geometry, in which the species transport equations were solved either to determine the RTD or to compute the $\mathrm{UV} / \mathrm{H}_{2} \mathrm{O}_{2}$ chemical reactions. The 3D CFD simulation is here denominated Coiled Microcapillary Model (CMM).

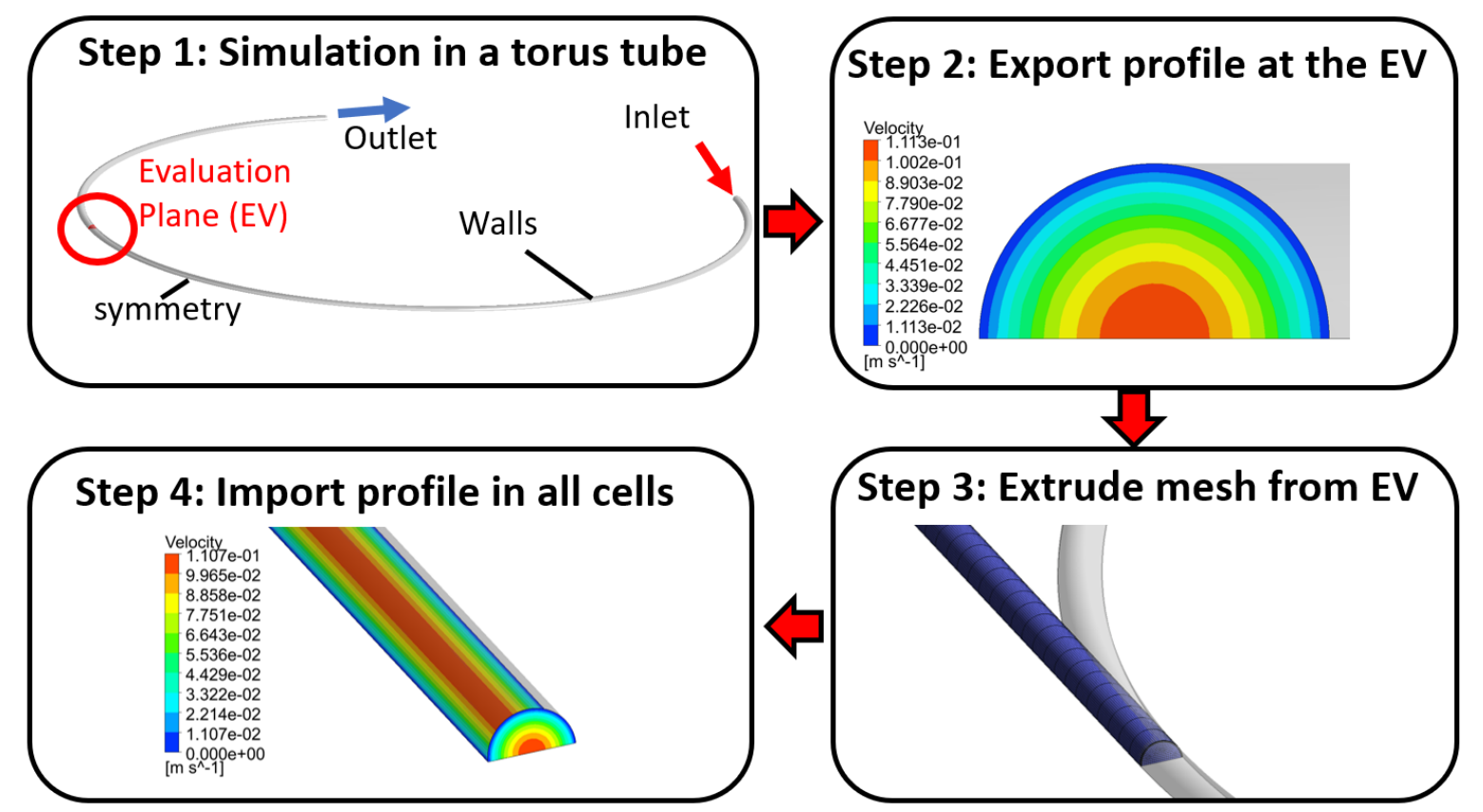

Fig. 2. Flowchart of the CFD model in the coiled microcapillary photoreactor (CMM).

The plane highlighted in red is the plane where velocity profile is extracted and where mesh is extracted to generate the straight-3D microcapillary. 
The advantage of the proposed approach is the use of higher aspect ratio cells along the microcapillary length while maintaining a degree of accuracy close to the complete geometry of the microcapillary. This approach neglects the torsion in the helical microcapillary, leading to a symmetric pair of Dean Vortices; valid when the ratio of pitch to coil radius is lower than unity [37]. As a result, the proposed methodology allows the use of a symmetry boundary condition, which additionally reduces by half the mesh size. It is estimated that this approach reduced the mesh size from 50 million elements to approximately 5 million elements. Note that this assumption is valid when $D_{L} \gg D_{\text {cap }}$, which was the case for all the evaluated scenarios. Further description of the numerical procedure, the validation of the CMM and the evaluation of mesh size independence are shown in Supplementary Information (SI) (Validation of the Coiled Microcapillary Model).

CFD simulations using a straight microcapillary were also evaluated (denominated Straight Microcapillary Model, SMM). In the SMM, the 2D axis symmetry was assumed, and the numerical domain could be significant reduced. The mesh size for the 2D-axisymmetric geometry had approximately 200 thousand elements, that is 25 times lower than the CMM. Moreover, simulations using the Plug flow model (PFM) were performed to be compared with the CFD analyses. The plug flow solutions were obtained using the stiff ODE solver in python code.

The boundary conditions of the fluid flow model were: (a) constant velocity at the reactor inlet; (b) constant pressure at the reactor outlet; (c) no-slip conditions at the walls of the reactor (d) symmetry at the center of the reactor. The boundary conditions adopted for the species transport equations were: (e) constant concentrations at the reactor inlet and (f) zerodiffusive flux at all other boundaries.

The flow was solved with convergence criterion as minimum residuals below $1 \cdot 10^{-6}$. For the species transport, the numerical method convergence criterion was taken as minimum 
residuals below $1 \cdot 10^{-6}$ and the time-step for the transient analyses (RTD studies) was $0.01 \mathrm{~s}$. For the execution of simulations, a computer with 8 processors Intel ${ }^{\circledR C}$ Core $^{\mathrm{TM}}$ i7 with $16 \mathrm{~GB}$ of usable RAM memory was used.

\subsubsection{Determination of kinetics constants}

The estimated parameters were the second-order kinetics constants of hydroxyl radical attack $\left(k_{O H}\right)$ to the micropollutant ACY, STV, ZDV, MIT, BIT and ISOX. Both micropollutant and hydroxy peroxide experimental concentrations were used to determine the $k_{O H}$ for each micropollutant. The kinetics constants were determined by the Least-Squares Regression, measuring the error between experimental $\left(\mathrm{Y}^{\mathrm{exp}}\right)$ and numerical mass fractions $\left(\mathrm{Y}^{\mathrm{CFD}}\right)$ using the Levenberg-Marquardt algorithm. The objective function used for the estimation of $k_{O H}$ was given by:

$$
F_{o b j}=\min \sum_{i=1}^{N_{e}} \sum_{j=1}^{N_{t}} \sum_{k=1}^{N_{s}}\left(\frac{Y_{i, j, k}^{C F D}-Y_{i, j, k}^{e x p}}{Y_{i, j=1, k}^{\exp }}\right)^{2}
$$

where $N_{e}$ is the number of experimental runs of the studied compound, $N_{t}$ is the number of measurements per experiment and $N_{S}$ is the number of chemical species (micropollutant and $\left.\mathrm{H}_{2} \mathrm{O}_{2}\right)$.

In Eq. (30), the difference between the experimental and numerical measurements were normalized by the initial mass fraction of each experimental run to weight equally the concentrations of the $\mathrm{H}_{2} \mathrm{O}_{2}$ and the micropollutant studied. This procedure was important due to different order of magnitude of the concentrations of $\mathrm{H}_{2} \mathrm{O}_{2}$, in the order of $\mathrm{mM}$, and the micropollutant, in the order of $\mu \mathrm{M}$. Note that the objective function differs from previous studies [22, 23, 24], which adopted an unweighted approach.

In summary, the estimation of $k_{O H}$ by the Coiled Microcapillary Model (CMM) took approximately 16 hours of CPU processing, whereas through Plug Flow Model (PFM) the 
kinetic constant was calculated in less than one minute. The estimation of $k_{O H}$ by the Straight Microcapillary Model (SMM) took approximately 2 hours, because of the lower computational cost of 2D simulations.

\section{Results and Discussion}

\subsection{Fluid dynamics in the microcapillary array}

The low Dean numbers $(D e<2)$ of the scenarios studied experimentally (see Table 1) suggest that the Dean vortices affected neither the axial velocity [26] nor the pressure drop in the microcapillary. This was confirmed by the CFD result of axial velocity for $R e=6.5$ and $R e=10.9\left(D_{\text {cap }}=195 \mu \mathrm{m}\right)$, shown in Fig. 3. The results show a parabolic axial velocity, as expected, however, it also revealed the noteworthy presence of Dean vortices in the microcapillaries. The pressure drop for $R e=6.5$ and $R e=10.9$ computed by CFD were 28.26 and $47.10 \mathrm{kPa} / \mathrm{m}$, respectively, confirming the neglected deviation from the Hagen-Poiseuille for straight tubes Eq. (31) of less than $0.03 \%$. Nevertheless, the Dean vortices enhance the radial mixing in the microcapillaries contributing to process intensification, even though the magnitude of the secondary flow velocity is a thousand-fold lower than the axial component.

$$
\Delta p=\frac{128 \mu L Q}{\pi D_{c a p}^{4}}
$$

\subsubsection{Residence Time Distribution (RTD)}

In addition to verification of the velocity field, the flow pattern in the microcapillary reactor can be characterized by the RTD. In a straight microcapillary, the dispersion of the tracer occurs by a combination of radial diffusion and axial convection, known as Taylor-Aris Dispersion [43]. The parabolic profile spread the tracer over the microcapillary length, whilst the radial diffusion limits the spread; since the tracer molecules at the center of the 
microcapillary travels much faster than the molecules near the wall, the average axial velocities of these molecules are reduced by the radial diffusion. In contrast, molecules near the wall diffuse radially toward the center. Thus, the Taylor-Aris Dispersion can generate a plug flow shape RTD with axial dispersion, provided that the space time is greater than the time required for the tracer to diffuse radially across the microcapillary. 

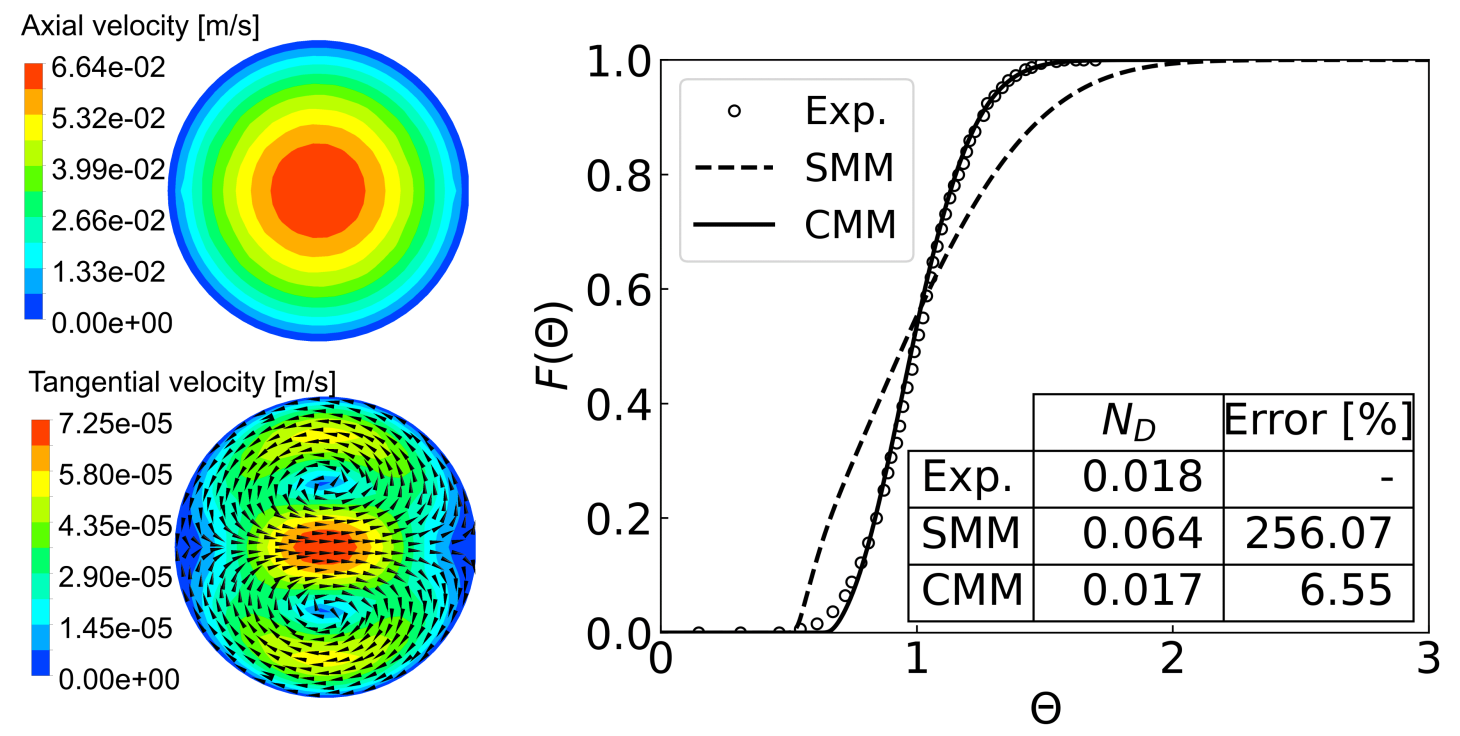

(a)
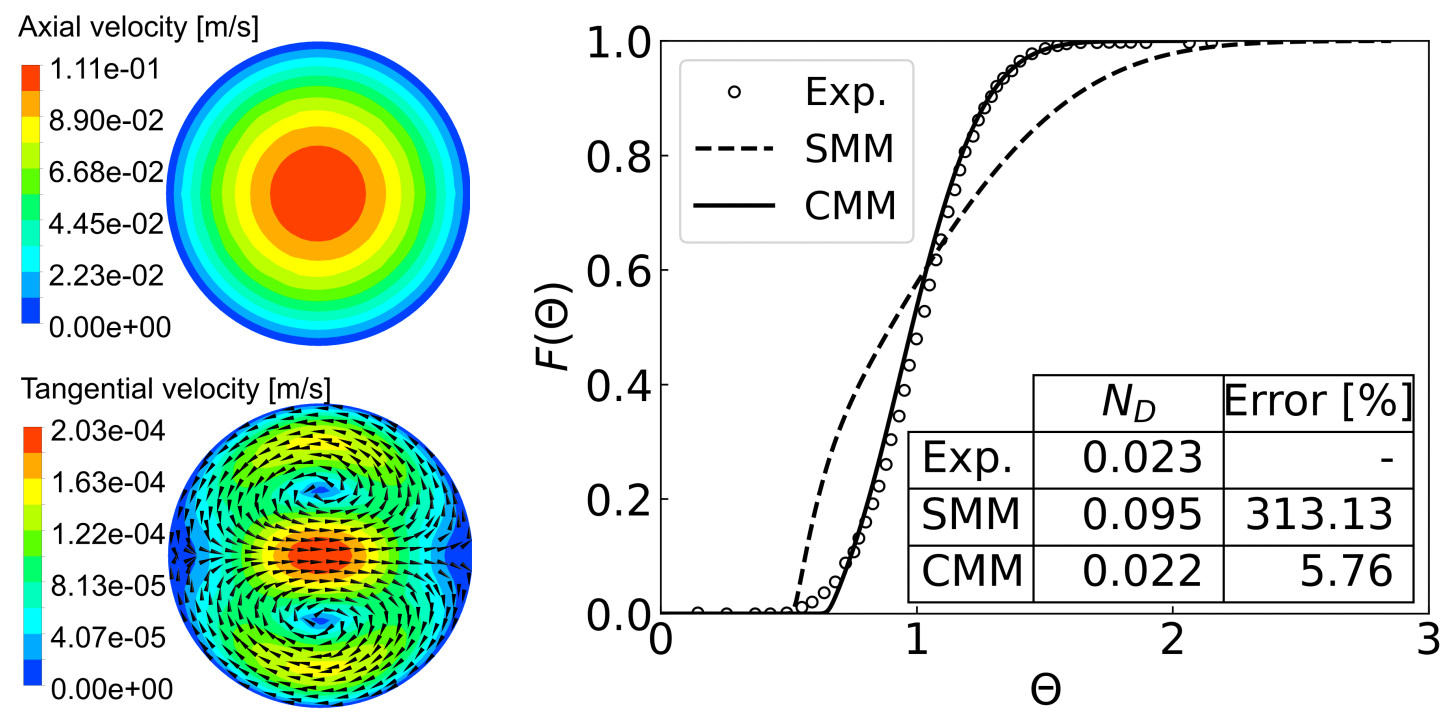

(b)

Fig. 3. Velocity profile (axial and tangential components), and Cumulative residence time distribution function of Blue Dextran 70 for $D_{\text {cap }}=195 \mu \mathrm{m}$, and Axial Dispersion Coefficient $\left(N_{D}\right)$ for the experiments, Straight Microcapillary Model and Coiled Microcapillary Model. (a) $Q=0.6 \mathrm{ml} / \mathrm{min}(R e=6.5)$ and (b) $Q=1.0 \mathrm{ml} / \mathrm{min}(R e=10.9)$.

However, in coiled microcapillaries, the dispersion of the tracer may not only be caused by the Taylor-Aris Dispersion, but also by the secondary flow. Apart from the radial diffusion, 
the tracer follows the Dean vortices streamlines, which can significantly improve the mixing over the radial direction.

Fig. 3 also shows the cumulative RTD obtained using the Straight Microcapillary Model (SMM) and using the Coiled Microcapillary Model $(\mathrm{CMM})$ for $R e=6.5$ and for $R e=$ $10.9(D e=0.7$ and $D e=1.2$, respectively). Compared with the experimental measurements, the RTD by the CMM showed an excellent agreement, whereas the RTD obtained by the SMM strongly differed from the experimental curve. Consistently, the CMM results accurately predicted the experimental curves for both $R e$, presenting an RTD characterized by a plug flow reactor with axial dispersion. On the other hand, the RTD computed by the SMM exhibited a pattern close to a laminar flow reactor. Thus, the results shown in Fig. 3 revealed that the secondary flow remarkably alters the shape of the RTD towards plug flow, which can contribute to the process intensification of the $\mathrm{UV}_{254} / \mathrm{H}_{2} \mathrm{O}_{2}$ process in microcapillary arrays photoreactors.

Additionally, Fig. 3 shows the $N_{D}$ calculated from the experiments, $N_{D}$ calculated from the numerical simulations (SMM and CMM), and the relative difference of the models from the experimental data. Quantitatively, the axial dispersion number $\left(N_{D}\right)$ for the CMM were 4fold lower than for the SMM. The relative different of $N_{D}$ between the CMM and the experiments were 6.55 and $5.76 \%$ for $R e=6.5$ and $R e=10.9$, respectively, while the relative difference between the SMM model and the experiments were 256 and $313 \%$. The excellent agreement for both $R e$ validated the CMM and demonstrated its reliability to compute the reacting flow in the microcapillary array technology.

\subsection{Evaluation of the transport phenomena in microcapillary}

Given that the secondary flow can contribute to process intensification in microreactors, it is essential to understand the conditions that favours such occurrence. To accomplish this, 
the RTD of Blue Dextran 70 was numerically studied for $R e$ ranging from 1 to $80\left(D_{\text {cap }}=200\right.$ $\mu \mathrm{m})$, and it was evaluated at several measurement planes along the microcapillary length to predict the variation of the axial dispersion coefficient, $D_{e f f}$, due to the secondary flow. Then, the mixing intensification was quantified by the ratio between the $D_{\text {eff }}$ in the coiled microcapillary and the axial dispersion coefficient in a straight microcapillary $\left(D_{s}\right)$. Note that when $D_{e f f} / D_{s}=1$ secondary flow has a negligible impact on process intensification, while $D_{\text {eff }} / D_{s}<1$ indicates a mixing enhancement.

Fig. 4 shows the dependence of $D_{e f f} / D_{s}$ on the space time for $R e$ in the range from 1 to 80 ( $D e$ from 0.11 to 8.94 ). The results showed that $D_{e f f} / D_{s}$ varies from 1 , at the entrance region of the microcapillary and reaches a pseudo-plateau value lower than 1 far from the entrance, which determines the extent of process intensification in terms of enhanced radial mixing. The amplitude of process intensification, for each $R e$, can be explained by the steady combination of secondary flow and mass diffusion. The results clearly show that the maximum change of $D_{e f f} / D_{s}$ from unity strongly depended on $D e$. For example, $D_{e f f} / D_{s}$ for $D e=0.7$ $(R e=6.5)$ was 9 times higher than the $D_{e f f} / D_{s}$ for $D e=8.94(R e=80)$. In addition, for $R e=1(D e=0.11), D_{e f f} / D_{s}$ was approximately 1 due to the weak effect of the secondary flow. 


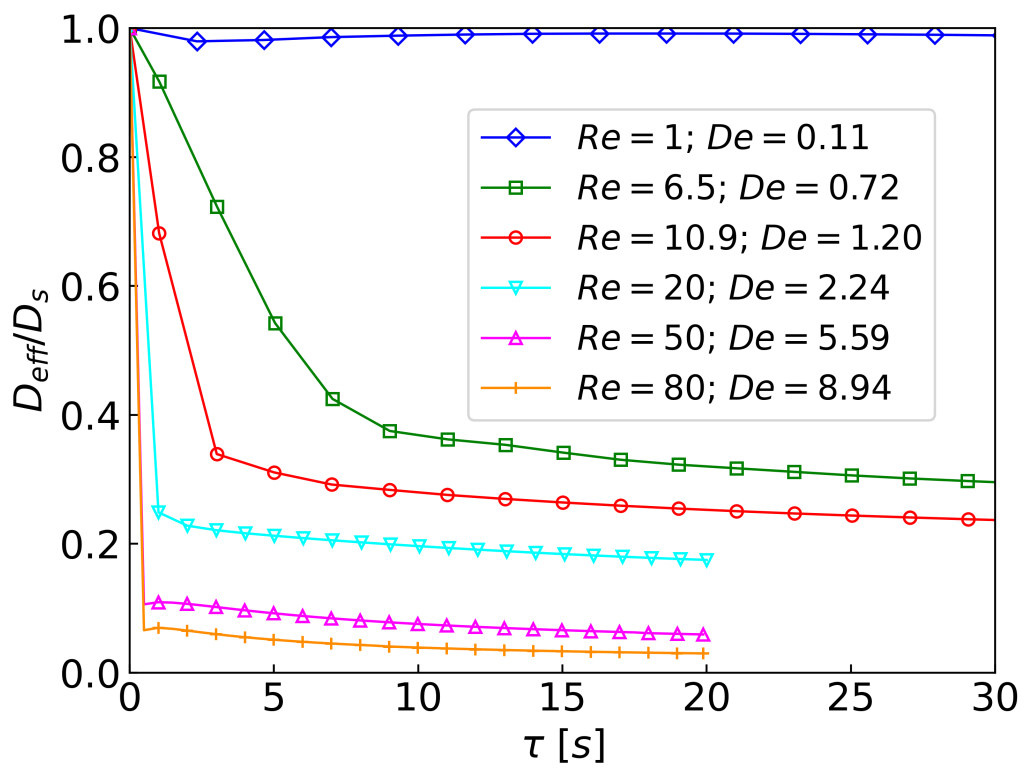

Fig. 4. Ratio between axial dispersion coefficient of Blue Dextran 70 in the coiled microcapillary and the axial dispersion coefficient in a straight pipe $\left(D_{e f f} / D_{S}\right)$ over the space time, for $R e$ from 1 to $80 . D_{\text {cap }}=200 \mu \mathrm{m}$.

The timescales of radial diffusion, secondary flow and space time determined the impact of Dean vortices on the tracer dispersion. The radial diffusion timescale can be computed by $D_{c a p}^{2} / D_{k, m}$, and the timescale of the secondary flow, herein defined as swirl timescale, can be defined as $\tau_{\text {swirl }}=D_{\text {cap }} / u_{\text {swirl }}$, where $u_{\text {swirl }}$ was calculated by the massweighted average of the tangential velocity. Relating both timescales yield a radial Peclet number: the ratio between the diffusion and swirl timescales (or the ratio between the swirl rate and diffusion rate), which allows an effective prediction of whether the secondary flow should be account for in numerical studies. For example, when the swirl timescale is much higher than the diffusion timescale, the secondary flow can be neglected, however, if the swirl timescale is lower than the diffusion timescale, then it contributes to the process intensification. Thus, a correlation is here proposed to estimate the swirl timescale and the swirl-to-diffusion ratio (radial Peclet) as function of Dean and Schmidt numbers: 


$$
\begin{aligned}
& \tau_{\text {swirl }}=\frac{D_{c a p}^{2}}{0.015 D e^{1.94}(\mu / \rho)} \\
& \frac{u_{\text {swirl }} D_{\text {cap }}}{D_{k, m}}=0.015 D e^{1.94} S c
\end{aligned}
$$

where $(0.015 \pm 0.001)$ and $(1.94 \pm 0.04)$ are model constants.

The constants of the Eqs. (32)-(33) were determined by least-squares regression $\left(R^{2}=\right.$ 0.998) varying the microcapillary diameter (from 100 to $1000 \mu \mathrm{m}$ ), the Reynolds number $(R e$ from 1 to 80$)$ and the lamp radius (16 and $32 \mathrm{~mm}$ ). The proposed correlation agreed with previous studies, which reported that the controlling parameter of a mixing intensification in coiled microreactors is $D e^{2} S c$ ( $D e^{1.94} S c$ in this study), and reported that the secondary flow should be accounted for when $D e^{2} S c>100\left(D e^{1.94} S c>67\right.$ in this study) [39]. Nevertheless, the advantage of the proposed correlation is the given physical meaning of the dimensionless number $D e^{1.94} S c$, in addition to the evaluation whether secondary flow should be considered. Fig. 5 shows the correlation of the swirl-to-diffusion ratio for $0.05<D e<20$.

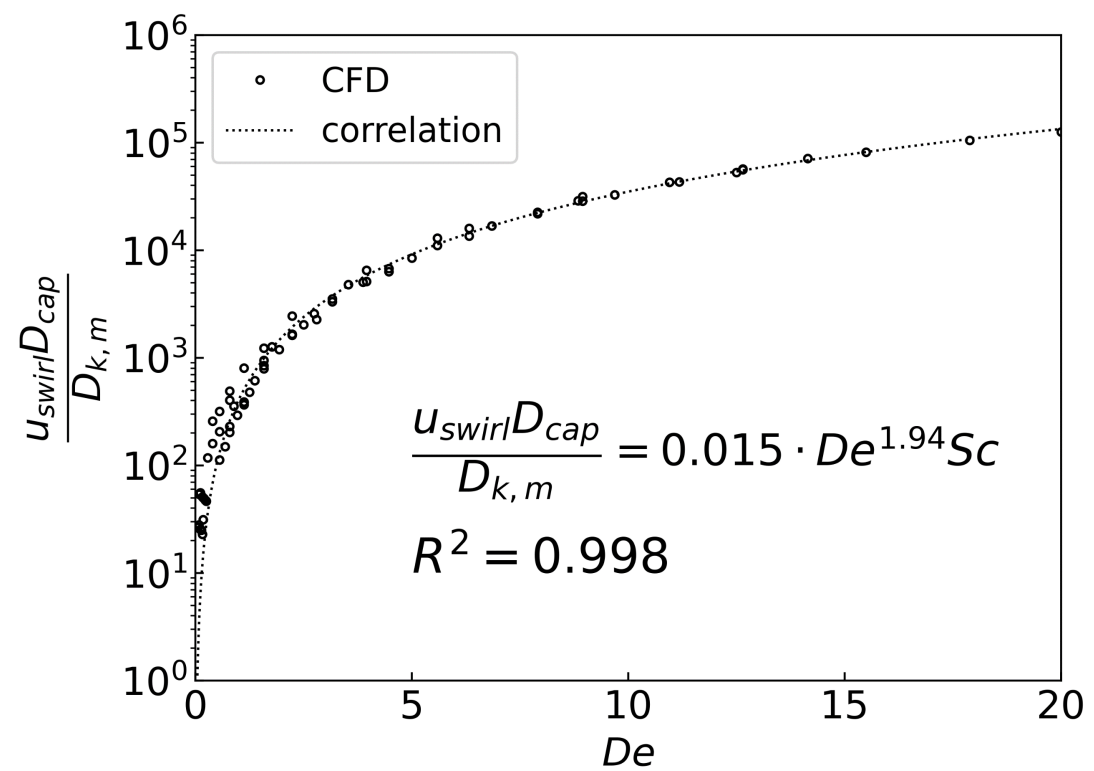

Fig. 5. Swirl-to-diffusion ratio in coiled microcapillaries as function of Dean number $\left(D_{k, m}=3.8 \cdot 10^{-7} \mathrm{~cm}^{2} / \mathrm{s}\right)$. 
Taking into account the swirl timescale and the swirl-to-diffusion ratio, a closer examination in Fig. 4 shows that the $D_{e f f} / D_{s}$ decreased to values lower than 1 when $\tau>$ $\tau_{\text {swirl }}$. The swirl timescale for the simulations shown in Fig. 4, calculated by Eq. (32), ranged from 0.02 to $18.87 \mathrm{~s}$ for the lowest and highest $D e$. Therefore, $D_{e f f} / D_{s}$ rapidly decreased for the highest $D e$, and was not altered for the lowest $D e$. For example, at conditions adopted in experimental determinations of the intrinsic kinetics constants of different water pollutants ( $R e=6.5$ and $D e=0.7)[22,23,24], \tau_{\text {swirl }}$ was 3.31 , which was 8 -fold lower than the maximum space time shown in Fig. $4(\tau=30)$. As a result, mixing intensification by Dean Vortices is expected when the space time to remove the MP is greater than $\tau_{\text {swirl }}$. Furthermore, the results showed that for $\tau>3 \tau_{\text {swirl }}$, the RTD became substantially modified by the presence of the Dean vortices, although the maximum enhancement of mixing depended on the magnitude of $D e$, as previously described.

\subsection{Determination of intrinsic kinetics constants of photo peroxidation of micropollutants}

The second-order kinetic constant $\left(k_{O H}\right)$ of the reaction of $\mathrm{OH}^{\bullet}$ radicals with ACY, STV, ZDV, MIT, BIT and ISOX were determined by the Plug Flow Model (PFM), Straight Microcapillary Model (SMM) and Coiled Microcapillary Model (CMM) (Table 3). The relative errors compared to $\mathrm{CMM}$ are presented, since $\mathrm{CMM}$ gives a more reliable solution of convection, mass diffusion and secondary flow. 
Table 3. Intrinsic kinetic constants of the water pollutants by the $\mathrm{UV}_{254} / \mathrm{H}_{2} \mathrm{O}_{2}$ process determined by the Plug Flow Model (PFM), Straight Microcapillary Model (SMM) and Coiled Microcapillary Model (CMM). $R e=6.5(D e=0.7)$.

\begin{tabular}{|c|c|c|c|c|}
\hline MP & Model & $k_{O H}\left[\mathrm{M}^{-1} \mathrm{~s}^{-1}\right] \cdot 10^{9}$ & $R^{2}$ & $\begin{array}{l}\text { Deviation } \\
\text { from } \\
\text { CMM (\%) }\end{array}$ \\
\hline \multirow{3}{*}{$\mathrm{ACY}$} & PFM & $0.986 \pm 0.084$ & 0.992 & -4.39 \\
\hline & SMM & $1.073 \pm 0.097$ & 0.992 & 1.40 \\
\hline & CMM & $1.052 \pm 0.094$ & 0.992 & - \\
\hline \multirow{3}{*}{ STV } & PFM & $1.597 \pm 0.148$ & 0.996 & -10.54 \\
\hline & SMM & $1.839 \pm 0.204$ & 0.996 & 3.03 \\
\hline & $\mathrm{CMM}$ & $1.785 \pm 0.189$ & 0.996 & - \\
\hline \multirow{3}{*}{ ZDV } & PFM & $1.094 \pm 0.146$ & 0.996 & -16.73 \\
\hline & SMM & $1.381 \pm 0.212$ & 0.996 & 5.13 \\
\hline & CMM & $1.314 \pm 0.190$ & 0.996 & - \\
\hline \multirow{3}{*}{ MIT } & PFM & $2.783 \pm 0.312$ & 0.965 & -15.38 \\
\hline & SMM & $3.500 \pm 0.454$ & 0.967 & 6.41 \\
\hline & $\mathrm{CMM}$ & $3.289 \pm 0.408$ & 0.966 & - \\
\hline \multirow{3}{*}{ BIT } & PFM & $7.199 \pm 1.135$ & 0.982 & -37.93 \\
\hline & SMM & $11.895 \pm 2.862$ & 0.982 & 2.55 \\
\hline & CMM & $11.599 \pm 2.731$ & 0.983 & - \\
\hline \multirow{3}{*}{ ISOX } & PFM & $2.412 \pm 0.266$ & 0.978 & -12.48 \\
\hline & SMM & $2.792 \pm 0.354$ & 0.978 & 1.31 \\
\hline & CMM & $2.756 \pm 0.345$ & 0.978 & - \\
\hline
\end{tabular}


Although the PFM has been assumed in previous studies [22, 23, 24], the results showed that the neglection of shear flow, mass diffusion and secondary flow, led to underestimations of $k_{O H}$. from 4.4 , for the least reactive compound, to $37.9 \%$, for the most reactive compound. When only shear flow and mass diffusion is accounted for (SMM), the accuracy of $k_{O H}$. increased compared with PFM, however, the absence of the secondary flow led to overestimations of $k_{O H}$. from 1.4 to $6.4 \%$ for the least and most reactive compounds, respectively. Therefore, the results unveiled the importance of modeling all the transport phenomena in the microcapillary, including the Dean vortices particularly for highly reactive micropollutants. The chemical structure of the contaminants may be indicative of high or low reactivity with $\mathrm{OH}^{\cdot}$ radicals [49] and the need of accurate modeling of the micromixing in coiled photoreactors. It is noteworthy to report that computing kinetics constants by the CFD modeling of the MCF gives more accurate predictions compared to commonly used methods such as competition kinetics, since the latter does not include the contribution of MP transformation by direct photolysis [22] and it can be subject to the reliability of the experimental and analytical methods.

The need of the CMM is more evident when there is a combination of a very reactive micropollutant and a lower mass diffusivity (e.g., MIT, STV and ZDV), owning to the little space time for the Taylor-Aris Dispersion. On the other hand, 3D CFD simulations of the CMM were 10 -fold more time-consuming than the SMM and were 230 -fold more time-consuming than the PFM due to the mesh size required. Note that the kinetics constants shown in Table 3 differed from the previous works $[22,23,24]$ due to the different objective function for the Least-Square regression used to weight equally both species (micropollutant and $\mathrm{H}_{2} \mathrm{O}_{2}$ ).

Fig. 6 and Fig. 7 show the concentration of BIT and ACY, respectively, versus the space time for the PFM and the CMM, evaluated under different inlet concentrations of the micropollutant and $\mathrm{H}_{2} \mathrm{O}_{2}$. The BIT and ACY are shown since they had the highest and lowest 
differences between PFM and CMM, respectively. However, the results for the other studied micropollutants are shown in Fig. S5-S10 (SI). For the sake of comparison consistency, both models were simulated using the kinetic constant $\left(k_{O H}\right)$ determined by the CMM. 


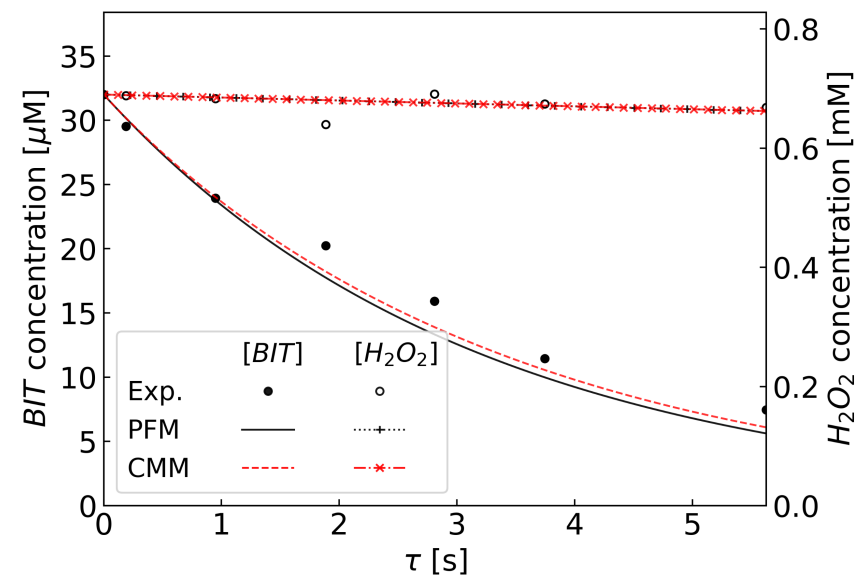

(a)

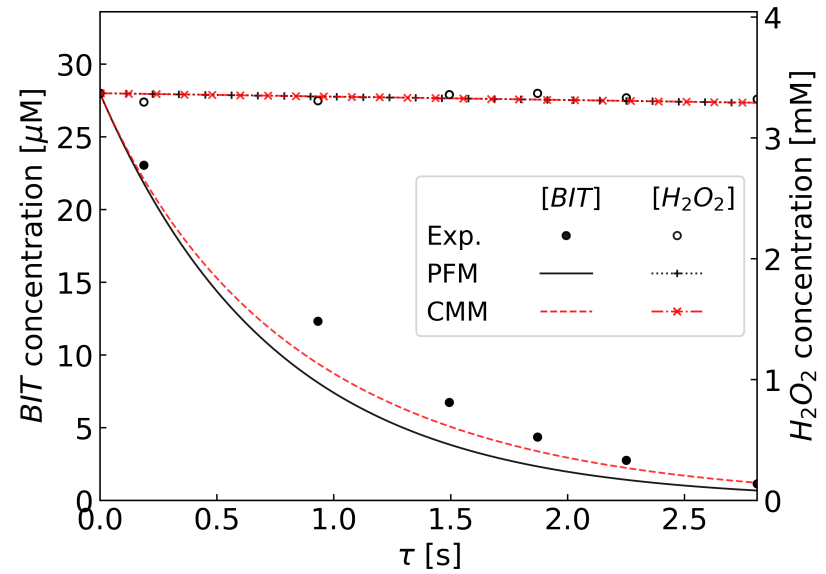

(b)

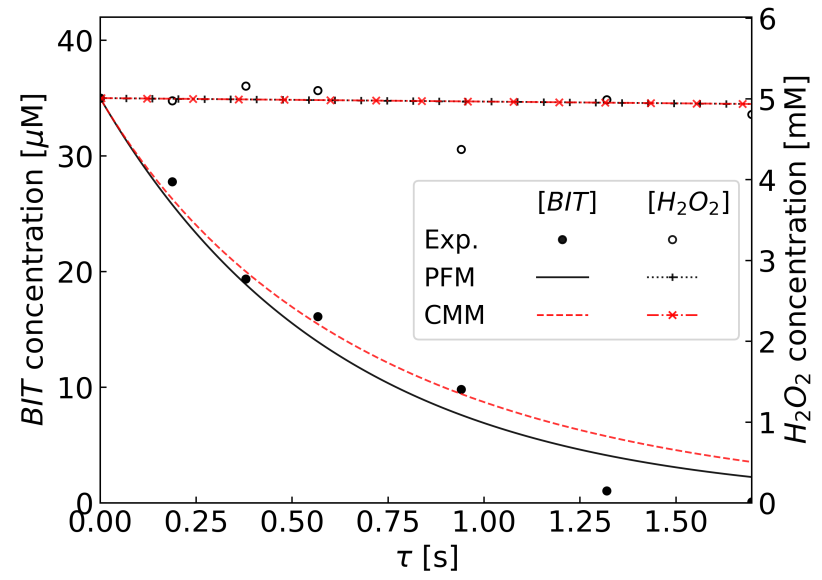

(c)

Fig. 6. Concentration of BIT and $\mathrm{H}_{2} \mathrm{O}_{2}$ versus space time for the PFM and CMM for different $\mathrm{H}_{2} \mathrm{O}_{2}$ initial concentration. $R e=6.5$ (De =0.7). Experimental data from [24] (a-b) $p H=6$ and (c) $p H=8 . P=8 \mathrm{~W}$. Complete matrix of simulations is shown in Fig. S9 (SI). 


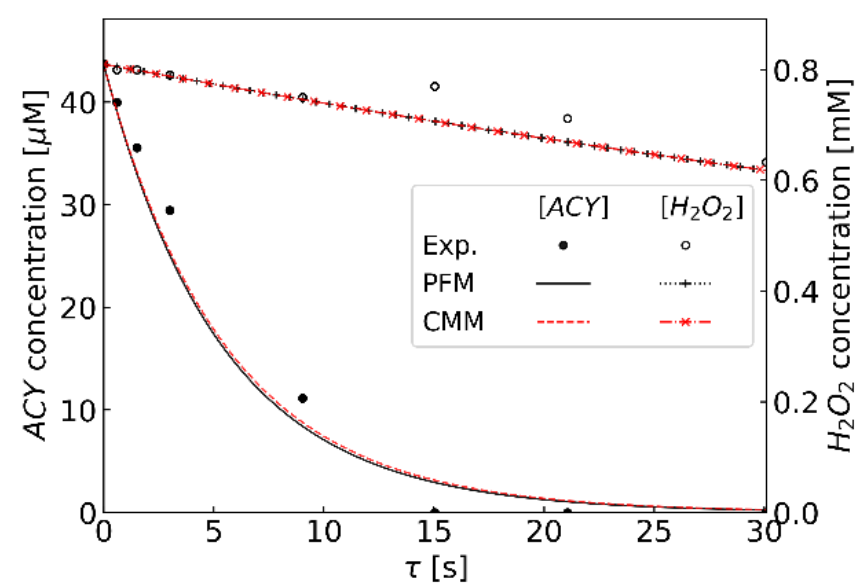

(a)

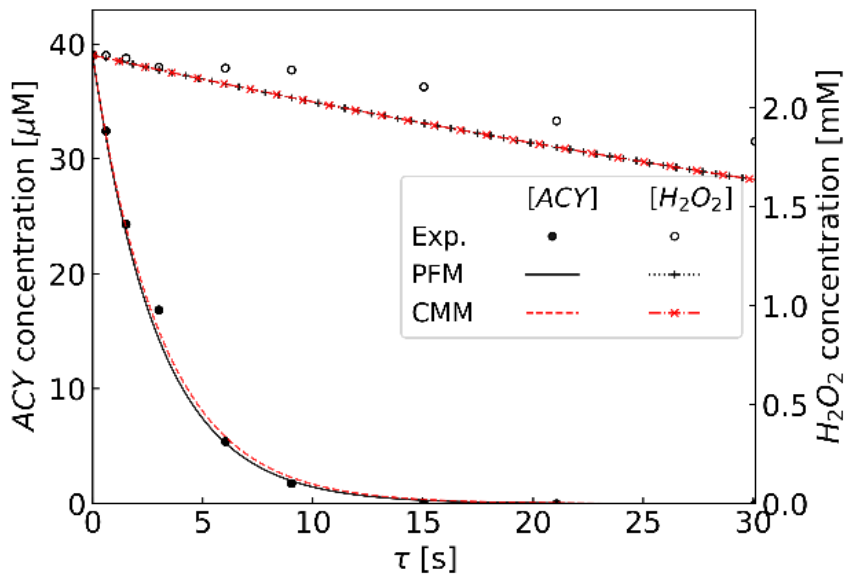

(b)

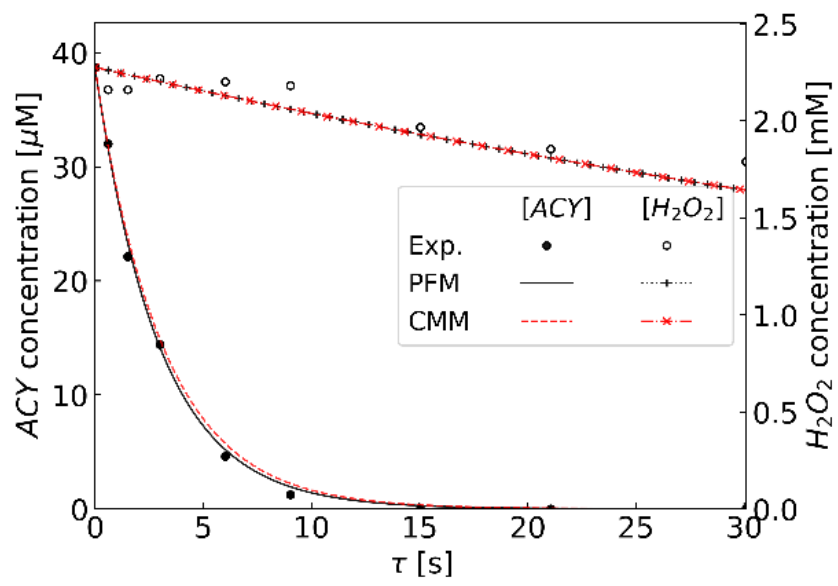

(c)

Fig. 7. Concentration of $\mathrm{ACY}$ and $\mathrm{H}_{2} \mathrm{O}_{2}$ versus space time for the PFM and CMM. $R e=6.5(D e=0.7)$. Experimental data from [22] (a-c) $p H=6 . P=8 \mathrm{~W}$. (a-c). Complete matrix of simulations is shown in Fig. S5 (SI). 
The results showed that the [BIT] obtained by the CMM differed from the PFM, while the $\left[\mathrm{H}_{2} \mathrm{O}_{2}\right]$ had a very close match for all studied conditions. Since both chemical compounds travelled under the same magnitude of secondary flow, the difference can be attributed to the more intense mass diffusion undergone by the $\mathrm{H}_{2} \mathrm{O}_{2}\left(D_{\mathrm{H}_{2} \mathrm{O}_{2}, \mathrm{~m}}=1.43 \cdot 10^{-5} \mathrm{~cm}^{2} / \mathrm{s}\right.$ mass diffusion and $D_{B I T, m}=7.29 \cdot 10^{-6} \mathrm{~cm}^{2} / \mathrm{s}$ ). It must be highlighted that the results in Fig. 6 and Fig. 7 were obtained for a swirl-to-diffusion ratio of $16\left(u_{s w i r l} D_{c a p} / D_{k, m}=16\right)$, indicating a mixing enhancement due to the secondary flow. However, the low reaction timescale of BIT (half-life time is approximately $0.5 \mathrm{~s}$ ) hindered a higher approximation with the plug flow. The swirl timescale was $3.31 \mathrm{~s}$, thus, the Dean vortices did not change the axial dispersion coefficient compared with a straight microcapillary (see Fig. 4).

Overall, the results demonstrated that higher errors on the estimation of the $k_{O H}$ might be found for more reactive micropollutants and when the radial diffusion is weak, i.e., compounds with low mass diffusivities or high microcapillary diameters. In contrast, for studies with slower kinetics and high radial diffusion rates, for example, in the case of direct photolysis of micropollutants, the PFM can accurately predict the degradation rate. This can be evidenced in the ACY removal by $\mathrm{UV} / \mathrm{H}_{2} \mathrm{O}_{2}$ in Fig. 7, in which the PFM and CMM curves were close.

\subsection{Evaluation of mass transfer limitations in the microcapillary array technology}

Owing to the simple design and ultrafast photo-transformation of micropollutants, the microcapillary array technology can be easily scaled-up by increasing the internal diameter and/or the number of microcapillaries [19]. However, mass transfer limitations of reacting species inside the photoreactor increase with microcapillary diameter. Hence, a sensitivity analysis was performed to evaluate the impact of the secondary flow on the photochemical 
peroxidation of water pollutants as function of the microcapillary diameter (from $100 \mu \mathrm{m}$ to $1000 \mu \mathrm{m})$, the Reynolds number and the lamp diameter. The mass transfer limitation was evaluated by comparisons of the results obtained using the CMM, with those results using PFM and using Laminar Flow Reactor Model (LFR). In the LFR, the mass diffusion and secondary flow are fully neglected, which represents the scenario with maximum mass transfer limitations.

Fig. 8 shows the concentration of Acyclovir, for CMM, PFM and LFR, over the space time for $D_{c a p}$ of 100,400 and $800 \mu \mathrm{m}$ and for $R e=1$ (Fig. 8 (a)), $R e=10$ (Fig. 8 (b)), $R e=$ 20 (Fig. 8 (c)) and $R e=80$ (Fig. 8 (d)). Acyclovir kinetics is presented herein since it is the most recalcitrant among the micropollutants studied. The results in Fig. 8 showed a negligible effect of the secondary flow for $R e=1$ (Fig. 8 (a)), however, as the Reynolds number increased, mass transfer limitations were reduced in the microcapillary reactor by means of Dean vortices. For instance, the removal rate of ACY was near the LFR curve for $D_{\text {cap }}=800$ $\mu \mathrm{m}$ and $R e=1(D e=0.22)$, and it increased up to the PFM curve under higher $R e(D e=$ 17.9). Nevertheless, smaller microcapillaries exhibited a removal rate close to the PFM for all $R e$, suggesting a higher sensitivity of $D_{c a p}$ compared to $D e$. 


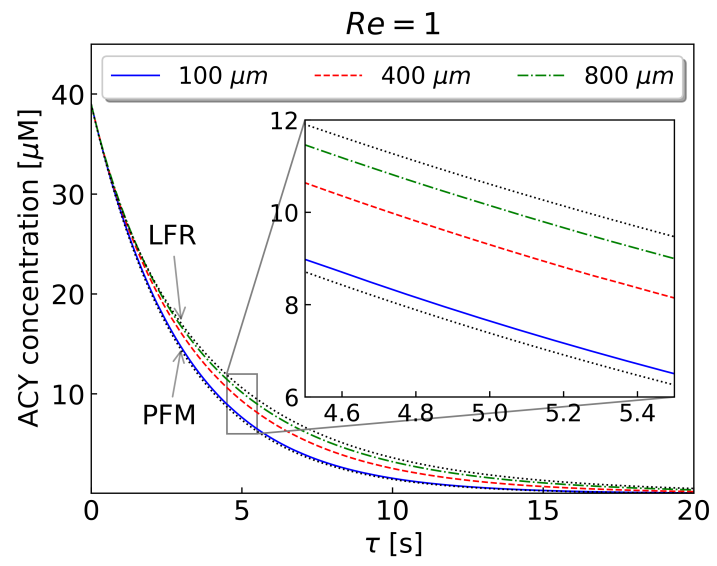

(a)

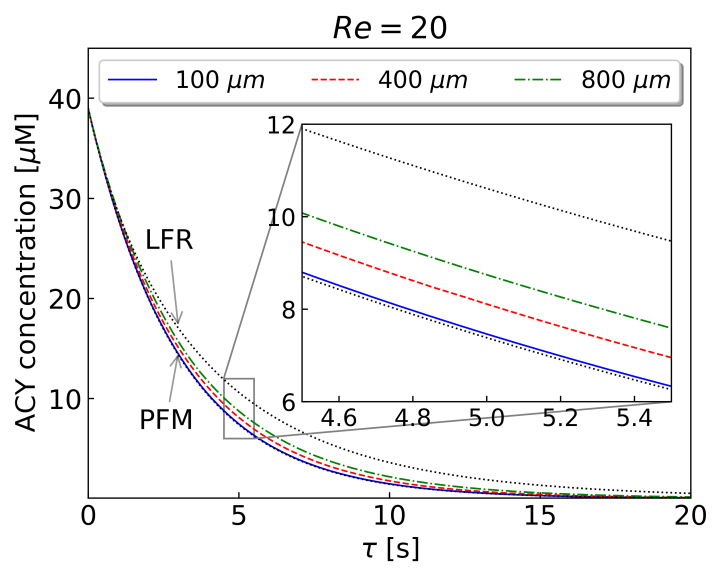

(c)

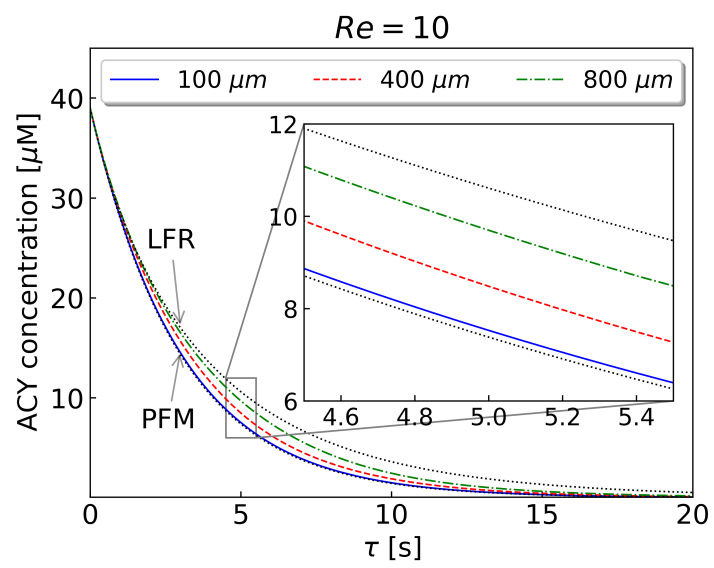

(b)

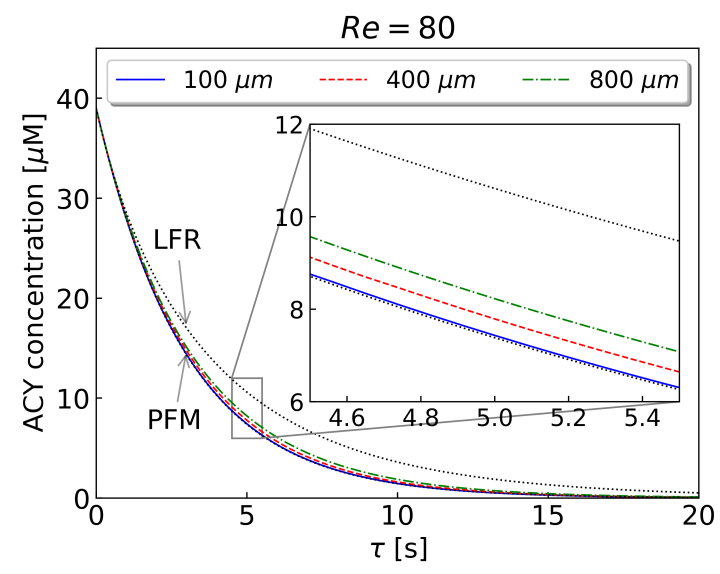

(d)

Fig. 8. Acyclovir concentration along microcapillary length for different microcapillary diameters and (a) $R e=1$, (b) $R e=10$, (c) $R e=20$ and (d) $R e=80 .[A C Y]_{0}=39.0 \mu \mathrm{m}$, $\left[\mathrm{H}_{2} \mathrm{O}_{2}\right]_{0}=2.3 \mathrm{mM}, P=8 \mathrm{~W}, p H=6$ and $D_{L}=16 \mathrm{~mm}$.

A closer examination in Fig. 8 also revealed a change in the degradation rate along the reactor length due to the secondary flow, which is more evident for $D_{c a p}=800 \mu \mathrm{m}$ under $R e=10$. In this case, the degradation rate was near the LFR at the entrance region of the microcapillary, and it increased towards the PFM after approximately 5 seconds. This can be explained by time needed to the reach the pseudo-plateau of $D_{e f f} / D_{s}$, shown in Fig. 4.

Contour plots of Acyclovir concentration in the microcapillary reactor are shown in Fig. 9 for $R e 1$ and 80, and $D_{\text {cap }} 100$ and $800 \mu \mathrm{m}$, and contour plots of $\left[\mathrm{H}_{2} \mathrm{O}_{2}\right]$ for the same simulations are shown in Fig. S11 (SI). The contour plots exhibit the concentration over the 
reactor length at two cut planes, where mass transfer limitations can be detected. The results in Fig. 9 (a) showed that $D_{\text {cap }}=100 \mu \mathrm{m}$ and $R e=1$ led to a negligible effect of the secondary flow (identified by the axis symmetry displayed) and had little mass transfer limitations because of the Taylor-Aris Dispersion. The scenario with the least mass transfer limitation, resembling a plug flow reactor, is shown in Fig. 9 (b), which underwent both effects of TaylorAris Dispersion and secondary flow. However, as previously discussed, mass transfer limitations were more evident when the microcapillary diameter increased. The absence of secondary flow led to a spread concentration of ACY over the length for low $R e$, whereas the secondary flow compensated the weak radial mass diffusion for high $\operatorname{Re}$ (See Fig. 9 (c-d)). 


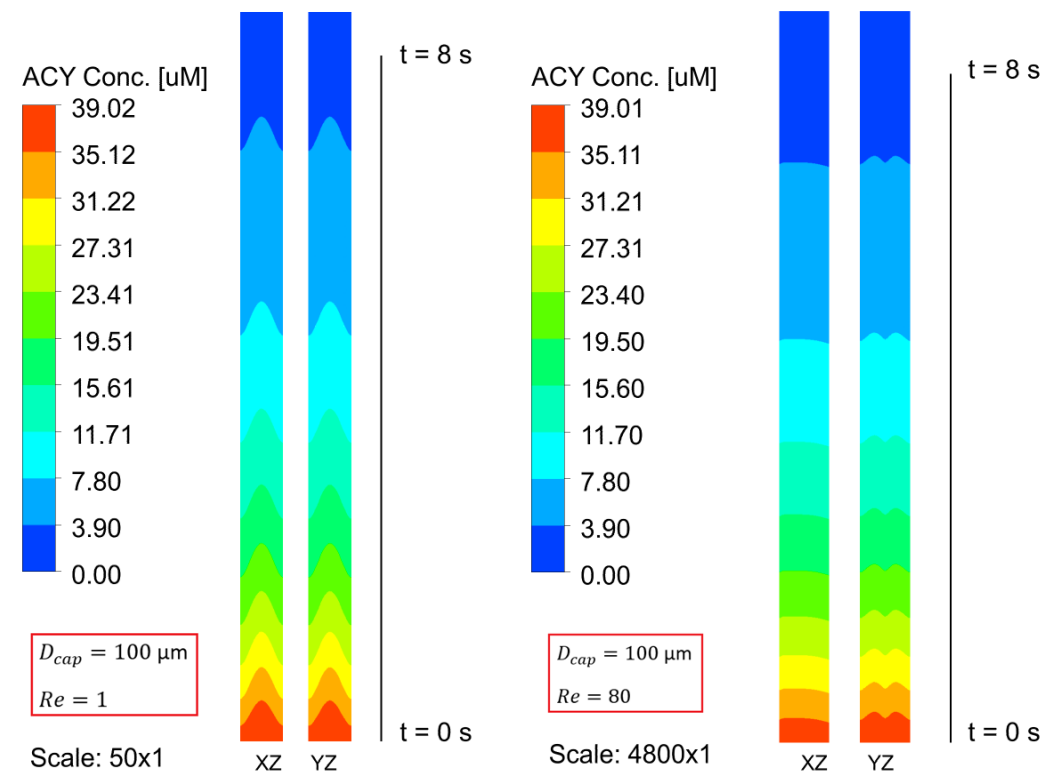

(a)

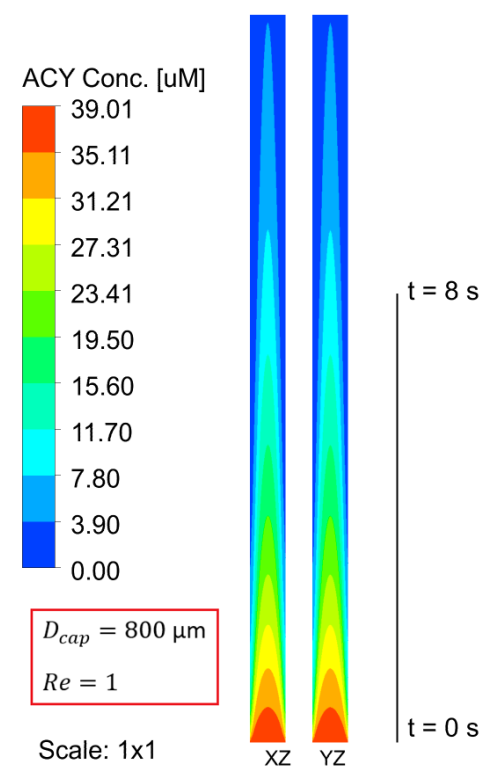

(c) (b)

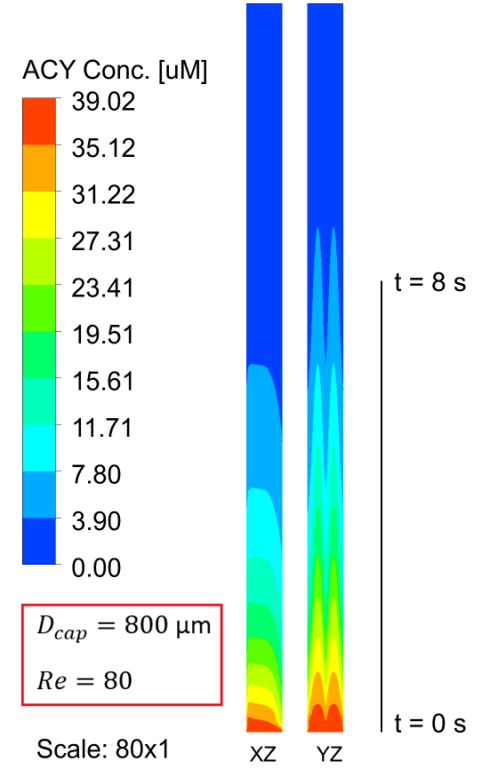

(d)

Fig. 9. Concentration of Acyclovir at $\mathrm{YZ}$ and $\mathrm{XZ}$ planes for (a) $D_{\text {cap }}=100 \mu \mathrm{m}$ and $R e=1$, (b) $D_{\text {cap }}=100 \mu \mathrm{m}$ and $R e=80$, (c) $D_{\text {cap }}=800 \mu \mathrm{m}$ and $R e=1$ and (d) $D_{\text {cap }}=$ $800 \mu \mathrm{m}$ and $R e=80\left([A C Y]_{0}=39.0 \mu \mathrm{m},\left[\mathrm{H}_{2} \mathrm{O}_{2}\right]_{0}=2.3 \mathrm{mM}, P=8 \mathrm{~W}, p H=6\right.$ and $D_{L}=$ $16 \mathrm{~mm}) . \mathrm{XY}$ and $\mathrm{XZ}$ planes were scaled to achieve better visualization and comparison among the MCFs simulations. 


\subsubsection{Electrical Energy per Order Reduction $\left(E_{E o}\right)$}

Additionally, mass transfer limitations of photochemical peroxidation process in the microcapillary array photoreactors were evaluated by means of the Electrical Energy per Order of Reduction $\left(E_{E O}\right)$ [50]. The $E_{E O}\left[\mathrm{kWh} \mathrm{m}^{-3}\right.$ per order] represents the energy input to the reactor that can achieve an order of magnitude decrease in concentration of a target contaminant in a unit volume, and can be used to compare the efficiency of different AOPs [51]. The $E_{E O}$ is calculated by:

$$
E_{E O}=\frac{P \cdot \tau_{1 / 10}}{V \cdot \log \left(C_{i} / C\right)}=P_{o} \cdot \tau_{1 / 10}
$$

where $\tau_{1 / 10}$ is the space time when the concentration $C$ is equal to one tenth of the inlet concentration $\left(C_{i}\right)$ in $[\mathrm{h}], P$ is the power emitted in $[\mathrm{kW}], V$ is the reactor volume in $\left[\mathrm{m}^{3}\right]$ and $P_{o}$ is the photon flux per unit volume in $\left[\mathrm{kW} / \mathrm{m}^{3}\right]$.

Fig. $10(\mathrm{a}-\mathrm{b})$ shows the ratio between the $E_{E O}$ computed by the CMM $\left(E_{E O, C M M}\right)$ and the $E_{E O}$ computed by the PFM $\left(E_{E O, P F M}\right)$ versus the swirl-to-diffusion ratio $\left(0.015 D e^{1.94} S c\right)$ for the $\mathrm{UV}_{254} / \mathrm{H}_{2} \mathrm{O}_{2}$ process of $\mathrm{ACY}$ and BIT in the coiled microcapillary. These were the pharmaceuticals with the lowest and highest $k_{O H}$, respectively. The results are presented for $D_{\text {cap }}$ from 100 to $1000 \mu \mathrm{m}$, for $R e$ from 1 to 80 and lamp diameter of $16 \mathrm{~mm}, 32 \mathrm{~mm}$ and $\infty$ $\mathrm{mm}$ (straight microcapillary). In addition, the $E_{E O, L F R} / E_{E O, P F M}$ is shown as a reference, as the LFR correspond to the maximum mass transfer limitation (38\% higher $E_{E O}$ ).

The results showed a negligible contribution of the secondary flow when the swirl-todiffusion ratio was lower or close to 1 , as expected. Under these conditions, Taylor-Aris dispersion is the driving force for the mixing over the radial direction. In contrast, for $0.015 D e^{1.94} S c>10$, it can be observed a process intensification effect, evidenced by a decrease on the $E_{E O, C M M} / E_{E O, P F M}$ to values close to 1 . Note that the swirl timescale increased with the microcapillary diameter (see Eq. (32)), thus, the secondary flow began enhancing the 
mixing in larger microcapillaries for greater values of $0.015 D e^{1.94} S c$. The results highlight the importance of modeling fluid dynamics and transport of species in the microcapillary array in order to accurately predict the removal rate in coiled microcapillary photoreactors, and to improve the degree of confidence for the evaluation of the intrinsic kinetics constants.

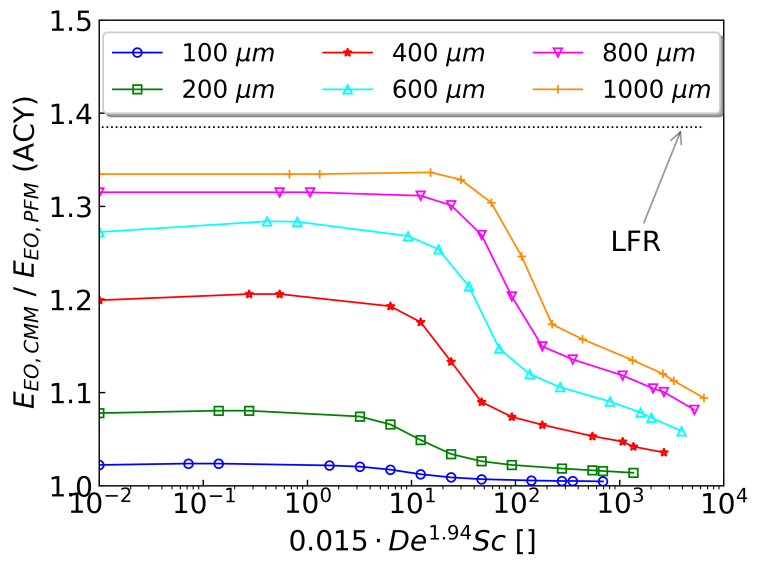

(a)

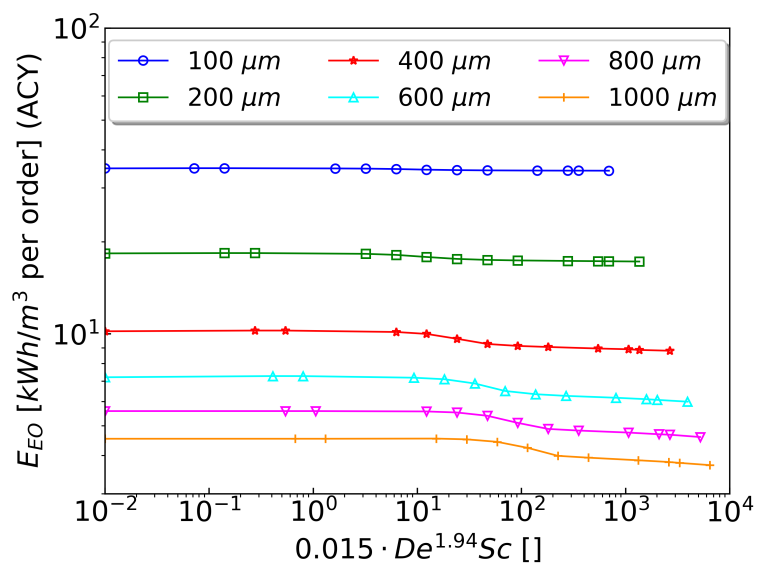

(c)

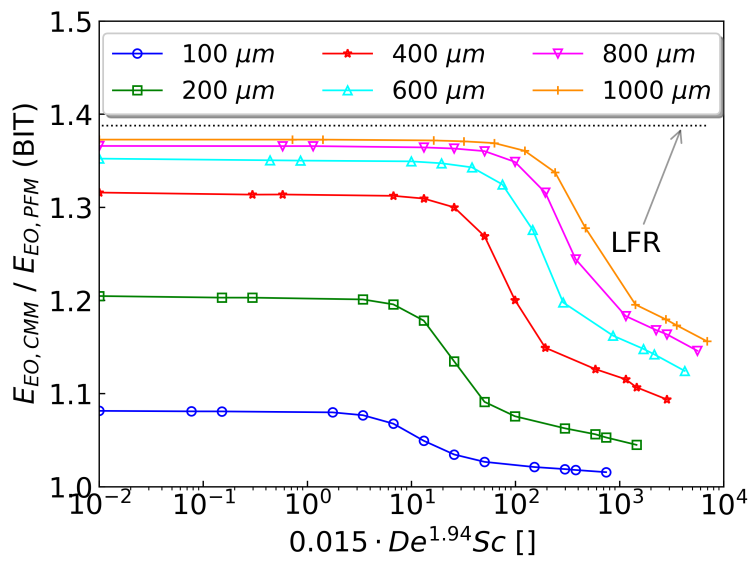

(b)

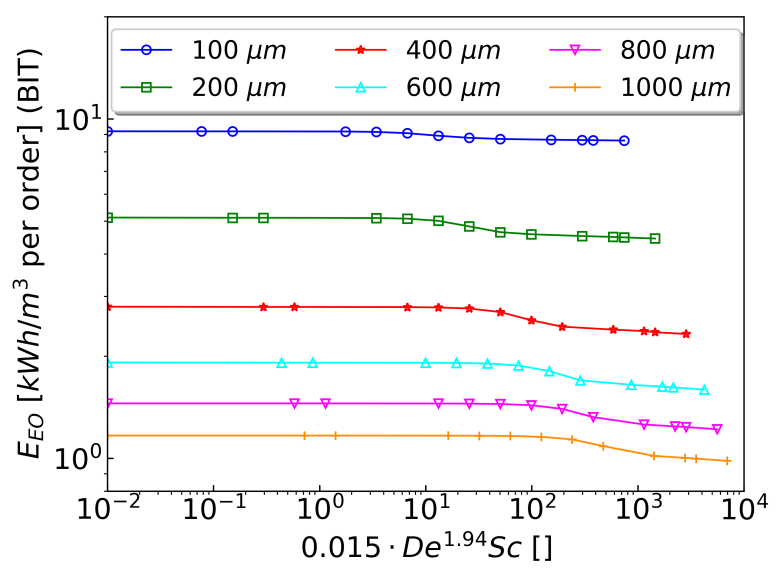

(d)

Fig. 10. (a-b) Ratio between the $E_{E O}$ computed by the CMM $\left(E_{E O, C M M}\right)$ and by the PFM ( $E_{E O, P F M}$ ) of (a) ACY and (b) BIT, and (c-d) $E_{E O, C M M}$ for (c) ACY and (d) BIT for different $D_{\text {cap }}(100$ to $1000 \mu \mathrm{m}), \operatorname{Re}(1$ to 80$)$ and $D_{L}(16$ or $32 \mathrm{~mm}) ;(\mathrm{a} / \mathrm{c}) \mathrm{ACY}:[A C Y]_{0}=39.0 \mu \mathrm{m}$, $\left[\mathrm{H}_{2} \mathrm{O}_{2}\right]_{0}=2.3 \mathrm{mM}, \mathrm{P}=8 \mathrm{~W}$ and $p H=6 ;(\mathrm{b} / \mathrm{d}) \mathrm{BIT}:[\mathrm{BIT}]_{0}=28.0 \mu \mathrm{m},\left[\mathrm{H}_{2} \mathrm{O}_{2}\right]_{0}=3.37$ $\mathrm{mM}, P=8 \mathrm{~W}$ and $p H=6$.

Also, the results showed that favouring radial dispersion (low $D_{c a p}$ ) reduce the mass transfer limitations in the microcapillary, however, the capillary diameter significantly impacts 
the magnitude of $E_{E O}$, since it is inversely proportional to the photoreactor volume (see Eq. (34)). An optimum design could be achieved by increasing the capillary diameter and increasing the contribution of secondary flow, in order to reach a significant reduction in $E_{E O}$, as shown in Fig. 10 (c-d). Furthermore, larger capillary diameters decrease pressure drop by a factor proportional to $1 / D_{\text {cap }}{ }^{4}$. Overall, the results demonstrated that MCF with larger capillary diameters reduce the $E_{E O}$ and the pressure drop, and also can achieve low mass transfer limitations, provided that the swirl-to-diffusion ratio is much higher than 1 . However, it should be noted that optimal $E_{E O}$ for the removal of CECs in actual wastewaters also depend on the operating conditions (e.g., pollutant load, UV dosage, concentration of $\mathrm{H}_{2} \mathrm{O}_{2}$ ) and on the water matrix composition, particularly in the presence of $\mathrm{OH}^{*}$ scavenging species.

\section{Conclusions}

This study has demonstrated the impact of secondary flow (Dean vortices) on the removal of pharmaceutical and CECs residues in water (Acyclovir, Stavudine, Zidovudine, Methylisothiazolinone, Benzisothiazolinone and Isoxazole) by photochemical peroxidation in helical microcapillary film photoreactors. It was established that coiling the microcapillaries around a cylindrical UV lamp can strongly favour radial mixing, which in turn increase mass transfer and the rate of removal of micropollutants. A novel CFD methodology for the solution in very high aspect ratio microcapillaries was proposed coupling species transport and the $\mathrm{UV}_{254} / \mathrm{H}_{2} \mathrm{O}_{2}$ chemical reaction mechanism. The CFD model enabled the determination of more accurate second-order reaction rate constants of the pharmaceuticals/CECs with $\mathrm{OH}^{\bullet}$ radicals $\left(k_{O H}\right)$. These were from $4.4 \%$ up to $37.9 \%$ higher than those determined assuming plug flow. A new correlation was proposed for the radial Peclet number $\left(u_{\text {swirl }} /\left(D_{\text {cap }} D_{k, m}\right)=0.015 D e^{1.94} S c\right)$, concluding that process intensification by Dean vortices occurs when $D e^{1.94} S c>67$. 
It was further shown that MCFs with larger capillary diameters reduce the pharmaceuticals $E_{E O}$ and pressure drop and can achieve low mass transfer limitations. The application of MCFs as highly effective systems to intensify chemical and biological reactions is recently gaining momentum, particularly in applications such as the ultrafast removal of CECs in water, viruses and bacteria, and the production of green chemicals and solar fuels. This study has shown how secondary flow induced by curvature in microreactors can be successfully exploited to design more efficient reaction systems.

\section{Acknowledgements}

This study was financed in part by the Coordenação de Aperfeiçoamento de Pessoal de Nível Superior (CAPES), Brazil (Finance Code 001). The authors also acknowledge iESSS (ESSS Institute for Education, Research and Development) for providing the software license to run ANSYS CFD package. 


\section{Nomenclature}

\begin{tabular}{|c|c|}
\hline$A$ & Area $\left[\mathrm{m}^{2}\right]$ \\
\hline$C_{k}$ & Concentration of $\mathrm{k}_{\text {th }}$ specie $[\mathrm{M}]$ \\
\hline$D_{e f f}$ & Effective axial diffusion coefficient $\left[\mathrm{cm}^{2} \mathrm{~s}^{-1}\right]$ \\
\hline$D_{s}$ & Axial diffusion coefficient in a straight microcapillary $\left[\mathrm{cm}^{2} \mathrm{~s}^{-1}\right]$ \\
\hline $\mathrm{D}_{k, \mathrm{~m}}$ & Mass diffusivity of specie $\mathrm{k}$ on mixture $\mathrm{m}\left[\mathrm{cm}^{2} \mathrm{~s}^{-1}\right]$ \\
\hline$D_{\text {cap }}$ & Microcapillary diameter $[\mu \mathrm{m}]$ \\
\hline$D_{L}$ & Lamp diameter $[\mathrm{mm}]$ \\
\hline$D e$ & Dean number \\
\hline$E(\theta)$ & Dimensionless residence time distribution function \\
\hline$E_{E O}$ & Electrical Energy per Order Reduction $\left[\mathrm{kWh} \mathrm{m}^{-3}\right.$ per order] \\
\hline$F(\theta)$ & Cumulative residence time distribution function \\
\hline$f_{k}$ & Fraction of absorbed energy by specie $\mathrm{k}$ \\
\hline$F_{k}$ & Rate of photolysis of specie $\mathrm{k}\left[\mathrm{M} \mathrm{s}^{-1}\right]$ \\
\hline $\mathrm{F}_{\text {obj }}$ & Objective function \\
\hline$k$ & Kinetic constant \\
\hline$L$ & Reactor length [mm] \\
\hline$l_{\text {cap }}$ & Average optical path length $[\mu \mathrm{m}]$ \\
\hline$M_{m, w}$ & Molecular weight of specie $\mathrm{k}\left[\mathrm{kg} \mathrm{kmol}^{-1}\right]$ \\
\hline$N_{e}$ & Number of experimental runs \\
\hline$N_{s}$ & Number of chemical species \\
\hline$N_{t}$ & Number of evaluated reaction times \\
\hline$N_{D}$ & Dimensionless dispersion number \\
\hline$p$ & Pressure $[\mathrm{Pa}]$ \\
\hline$P$ & Lamp power $[\mathrm{W}]$ \\
\hline$P_{0}$ & Photon flux per unit volume emitted $\left[\operatorname{ein~s}^{-1} \mathrm{~L}^{-1}\right]$ \\
\hline$q_{0}$ & Global photon flux $\left[\right.$ ein s$\left.^{-1}\right]$ \\
\hline$Q$ & Flow rate $\left[\mathrm{m}^{3} / \mathrm{s}\right]$ \\
\hline
\end{tabular}




\begin{tabular}{|c|c|}
\hline$\overline{r_{k}}$ & Net reaction rate for the reactant $\mathrm{k}\left[\mathrm{kmol} \mathrm{m}^{-3} \mathrm{~s}^{-1}\right]$ \\
\hline$R e$ & Reynolds number \\
\hline$S$ & Hydraulic area $\left[\mathrm{m}^{2}\right]$ \\
\hline$S c$ & Schmidt number \\
\hline$t$ & Time $[\mathrm{s}]$ \\
\hline$u_{i}$ & Velocity of ith direction $\left[\mathrm{m} \mathrm{s}^{-1}\right]$ \\
\hline$u_{\text {swirl }}$ & Swirl velocity $\left[\mathrm{m} \mathrm{s}^{-1}\right]$ \\
\hline$V_{r}$ & Reactor volume $\left[\mathrm{m}^{3}\right]$ \\
\hline$\overline{x_{i}}$ & Position in ith coordinate $[\mathrm{m}]$ \\
\hline$Y_{k}$ & Mass fraction of specie $\mathrm{k}$ \\
\hline \multicolumn{2}{|c|}{ Greek letters } \\
\hline$\epsilon_{k}^{254}$ & Molar absorption coefficient at $254 \mathrm{~nm}$ for $\mathrm{k}_{\mathrm{th}}$ specie $\left[\mathrm{M}^{-1} \mathrm{~cm}^{-1}\right]$ \\
\hline$\theta$ & Dimensionless time \\
\hline$\mu$ & Viscosity $[\mathrm{cP}]$ \\
\hline$\rho$ & Density $\left[\mathrm{kg} \mathrm{m}^{-3}\right]$ \\
\hline$\sigma_{\tau}^{2}$ & Variance of $\tau\left[\mathrm{s}^{2}\right]$ \\
\hline$\tau$ & Space time $[\mathrm{s}]$ \\
\hline$\overline{\tau_{\text {swirl }}}$ & Swirl timescale [s] \\
\hline$\phi$ & Quantum yield [mol ein $\left.{ }^{-1}\right]$ \\
\hline
\end{tabular}




\section{Bibliography}

A. Sharma, J. Ahmad, S. J. S. Flora, Application of advanced oxidation processes and toxicity assessment of transformation products, Environ. Res. 167 (2018) 223-233. https://doi.org/10.1016/j.envres.2018.07.010.

D. Kassinos, Removal of residual pharmaceuticals from aqueous systems by advanced oxidation processes, Environ. Int. 35 (2009) 402-417. https://doi.org/10.1016/j.envint.2008.07.009.

D. Kanakaraju, B. D. Glass, M. Oelgemoller, Advanced oxidation process-mediated removal of pharmaceuticals from water: A review, J. Environ. Manage. 219 (2018) 189-207. https://doi.org/10.1016/j.jenvman.2018.04.103.

A.-K. Ghattas, F. Fischer, A. Wick, T. A. Ternes, Anaerobic biodegradation of (emerging) organic contaminants in the aquatic environment, Water Res. 116 (2017) 268-295. https://doi.org/10.1016/j.watres.2017.02.001. contaminants in wastewaters and the environment: Current knowledge, understudied areas and recommendations for future monitoring, Water Res. 72 (2015) 3-27. https://doi.org/10.1016/j.watres.2014.08.053.

[6] W. Y. Lin, Y. Wang, S. Wang, H. R. Tseng, Integrated microfluidic reactors, $\quad$ Nano $\quad$ Today $\quad 4 \quad$ (2009) $\quad 470-481$. https://doi.org/10.1016/j.nantod.2009.10.007.

[7] T. Van Daele, D. Fernandes del Pozo, D. Van Hauwermeiren, K. V. Gernaey, R. Wohlgemuth, I. Nopens, A generic model-based methodology for 
quantification of mass transfer limitations in microreactors, Chem. Eng. J. 300 (2016) 193-208. https://doi.org/10.1016/j.cej.2016.04.117.

[8] H. Löwe, V. Hessel, A. Mueller, Microreactors. Prospects already achieved and possible misuse, Pure Appl. Chem., 74 (2002) 2271-2276. https://doi.org/10.1351/pac200274122271

[9] X. Zhang, S. Stefanick, F. J. Villani, Application of microreactor technology in process development, Org. Process Res. Dev. 8 (2004) 455-460. https://doi.org/10.1021/op034193x

[10] A. Gavriilidis, P. Angeli, E. Cao, K. Yeong, Y. S. S. Wan, Technology and applications of microengineered reactors, Chem. Eng. Res. Des. 80 (2002) 330. https://doi.org/10.1205/026387602753393196.

[11] V. J. P. Vilar, P. Alfonso-Muniozguren, J. P. Monteiro, J. Lee, M. S. Miranda, R. A. R. Boaventura, Tube-in-tube membrane microreactor for photochemical UVC/ $\mathrm{H}_{2} \mathrm{O}_{2}$ processes: A proof of concept, Chem. Eng. J. 379 (2020) 122341. https://doi.org/10.1016/j.cej.2019.122341.

A. Yusuf, H. Oladipo, L. Y. Ozer, C. Garlisi, V. Loddo, M. R. M. AbuZahra, G. Palmisano, Modelling of a recirculating photocatalytic microreactor implementing mesoporous $\mathrm{N}-\mathrm{TiO}_{2}$ modified with graphene, Chem. Eng. J. 391 (2020) 123574. https://doi.org/10.1016/j.cej.2019.123574.

[13] M. Oelgemöller, O. Shvydkiv, Recent advances in microflow $\begin{array}{lllll}\text { photochemistry, } & \text { Molecules, } & 16 & \text { (2011) }\end{array}$ https://doi.org/10.3390/molecules16097522. 
M. Oelgemoeller, Highlights of Photochemical Reactions in Microflow

Reactors, Chem. Eng. Technol. $35 \quad$ (2012) 1144-1152. https://doi.org/10.1002/ceat.201200009.

Transformations Accelerated in Continuous-Flow Reactors: Basic Concepts and Applications, Chemistry Eur. J. $20 \quad$ (2014) 10562-10589. https://doi.org/10.1002/chem.201400283.

T. Noël, A Personal Perspective on the Future of Flow Photochemistry, J.

Flow Chem. 7 (2017) 87-93. https://doi.org/10.1556/1846.2017.00022.

Berli, Simple method for the assessment of intrinsic kinetic constants in photocatalytic microreactors, Appl. Catal. B 241 (2019) 8-17. https://doi.org/10.1016/j.apcatb.2018.09.015. E. Kayahan, M. Jacobs, L. Braeken, L. C. J. Thomassen, S. Kuhn, T. van Gerven, M. E. Leblebici, Dawn of a new era in industrial photochemistry: the scale-up of micro- and mesostructured photoreactors, Beilstein J. Org. Chem. 16 (2020) 2484-2504. https://doi.org/10.3762/bjoc.16.202.

[19] N. M. Reis, G. Li Puma, A novel microfluidic approach for extremely fast and efficient photochemical transformations in fluoropolymer micro capillary films, Chem. Commun. $51 \quad$ (2015) 8414-8417. https://doi.org/10.1039/c5cc01559f.

[20] D. Russo, D. Spasiano, M. Vaccaro, R. Andreozzi, G. Li Puma, N. M. Reis, R. Marotta, Direct photolysis of benzoylecgonine under UV irradiation at 
$254 \mathrm{~nm}$ in a continuous flow microcapillary array photoreactor, Chem. Eng. J. 286 (2016) 243-250. https://doi.org/10.1016/j.cej.2015.07.061

D. Spasiano, D. Russo, M. Vaccaro, A. Siciliano, R. Marotta, M. Guida, N. M. Reis, G. Li Puma, Removal of benzoylecgonine from water matrices through $\mathrm{UV}_{254} / \mathrm{H}_{2} \mathrm{O}_{2}$ process: Reaction kinetic modeling, ecotoxicity and genotoxicity assessment, J. Hazard. Mater. 318 (2016) 515-525. https://doi.org/10.1016/j.jhazmat.2016.07.034. D. Russo, A. Siciliano, M. Guida, E. Galdiero, A. Amoresano, R. Andreozzi, N. M. Reis, G. Li Puma, R. Marotta, Photodegradation and ecotoxicology of acyclovir in water under $\mathrm{UV}_{254}$ and $\mathrm{UV}_{254} / \mathrm{H}_{2} \mathrm{O}_{2}$ processes, Chem. Eng. J. 122 (2017) 519-602. https://doi.org/10.1016/j.watres.2017.06.020. D. Russo, A. Siciliano, M. Guida, R. Andreozzi, N. M. Reis, G. Li Puma, R. Marotta, Removal of antiretroviral drugs stavudine and zidovudine in water under $\mathrm{UV}_{254}$ and $\mathrm{UV}_{254} / \mathrm{H}_{2} \mathrm{O}_{2}$ processes: Quantum yields, kinetics and ecotoxicology assessment, J. Hazard. Mater 349 (2018) 195-204. https://doi.org/10.1016/j.jhazmat.2018.01.052. D. Russo, K. H. Cochran, D. Westerman, G. Li Puma, R. Marotta, R. Andreozzi, S. D. Richardson, Ultrafast photodegradation of isoxazole and isothiazolinones by $\mathrm{UV}_{254}$ and $\mathrm{UV}_{254} / \mathrm{H}_{2} \mathrm{O}_{2}$ photolysis in a microcapillary reactor, Water Res. 169 (2020) 115203. https://doi.org/10.1016/j.watres.2019.115203. L. A. M. Janssen, Axial dispersion in laminar flow thorugh coiled tubes, Chem. Eng. Sci. $31 \quad$ (1976) 215-218. https://doi.org/10.1016/00092509(76)85059-2. 
Scale Determination in Microchannels Using Reaction Calorimetry, Chemie Ingenieur Technik 5 (2019) 622-631. https://doi.org/10.1002/cite.201800169.

[27] L. Sharma, K. Nigam, S. Roy, Single phase mixing in coiled tubes and coiled flow inverters in different flow regimes, Chem. Eng. Sci. 160 (2017) 227235. https://doi.org/10.1016/j.ces.2016.11.034.

[28] D. Rossi, L. Gargiulo, G. Valitov, A. Gavriilidis, L. Mazzei, Experimental characterization of axial dispersionin coiled flow inverters, Chem.Eng. Res. Des. 120 (2017) 159-170. https://doi.org/10.1016/j.cherd.2017.02.011.

[29] Z. Y. Zhu, CFD Simulation in Helical Coiled Tubing, J. Appl. Sci. Eng. 19 (2016) 267-272. https://doi.org/10.6180/jase.2016.19.3.04.

[30] O. Abushammala, R. Hreiz, C. Lemaître, E. Favre, Laminar flow friction factor in highly curved helical pipes: Numerical investigation, predictive correlation and experimental validation using a 3D-printed model, Chem. Eng. Sci. 207 (2019) 1030-1039. https://doi.org/10.1016/j.ces.2019.07.018. device for process intensification, Chem. Eng. Process. 86 (2014) 78-89. https://doi.org/10.1016/j.cep.2014.10.013. helical heat/mass exchangers under laminar flow: CFD investigation and correlations for maximal transfer efficiency and process intensification performances, Int. J. Heat Mass Trans $153 \quad$ (2020) 119610. https://doi.org/10.1016/j.ijheatmasstransfer.2020.119610. 

inverter for process intensification, Chem. Eng. Sci. 193 (2019) 312-324. https://doi.org/10.1016/j.ces.2018.09.008. Comparative assessment of mixing in compact coiled flow inverters under diffusion free laminar flow condition, Chem. Eng. Res. Des. 159 (2020) 455-467. https://doi.org/10.1016/j.cherd.2020.04.028. as an innovative static mixer in laminar flows, Chem. Eng. J. 359 (2019) 446-458. https://doi.org/10.1016/j.cej.2018.11.048.

P. Khot, M. Mansour, D. Thévenin, K. D. P. Nigam, K. Zähringera, Improving the mixing characteristics of coiled configurations by early flow inversion, Chem. Eng. Res. Des. $146 \quad$ (2019) 324-335. https://doi.org/10.1016/j.cherd.2019.04.016.

[37] M. Mansour, Z. Liu, G. Janiga, K. D. P. Nigam, K. Sundmacher, D. Thévenin, K. Zähringer, Numerical study of liquid-liquid mixing in helical pipes, Chem. Eng. Sci. 172 (2017) 250-261. https://doi.org/10.1016/j.ces.2017.06.015. M. Mansour, P. Khot, D. Thévenin, K. D. P. Nigam, K. Zähringer, Optimal Reynolds number for liquid-liquid mixing in helical pipes, Chem. Eng. Sci. 214 (2020) 114522. https://doi.org/10.1016/j.ces.2018.09.046.

[39] M. Johnson, R. D. Kamm, Numerical studies of steady flow dispersion at low Dean number in a gently curving tube, J. Fluid Mech. 172 (1986) 329-345. https://doi.org/10.1017/S0022112086001763. 
in Curved Tubes, AICHE J. $34 \quad$ (1988) 2052-2058. https://doi.org/10.1002/aic.690341214.

[41] A. Choudhary, S. Pushpavanam, Process intensification by exploiting Dean vortices in catalytic membrane microreactors, Chem. Eng. Sci. 174 (2017) 413-425. https://doi.org/10.1016/j.ces.2017.09.005. ANSYS, ANSYS Documentation. https://ansyshelp.ansys.com/. (June accessed 2020).

[43] O. Levenspiel, Chemical Reaction Engineering, 3rd ed., New York: John Wiley and Sons, 1999.

[44] D. Spasiano, A. Siciliano, M. Race, R. Marotta, M. Guida, R. Andreozzi, F. Pirozzi, Biodegradation, ecotoxicity and $\mathrm{UV}_{254} / \mathrm{H}_{2} \mathrm{O}_{2}$ treatment of imidazole, 1-methyl-imidazole and N,N'-alkyl-imidazolium chlorides in water, Water Res. 106 (2016) 450-460. https://doi.org/10.1016/j.watres.2016.10.026.

S. Goldstein, D. Aschengrau, Y. Diamant, J. Rabani, Photolysis of aqueous $\mathrm{H}_{2} \mathrm{O}_{2}$ : quantum yield and applications for polychromatic UV actinometry in photoreactors, Environ. Sci. Technol. 41 (2007) 7486-7490. https://doi.org/10.1021/es071379t. review of rate constants for reactions of hydrated electrons, hydrogen atoms and hydroxyl radicals $(\mathrm{OH} / \mathrm{O})$ in aqueous solution, J. Phys. Chem. Ref. Data 17 (1988) 513-886. https://doi.org/10.1063/1.555805. 

radicals in aqueous solution, J. Phys. Chem. Ref. Data 14 (1985) 1041-1077. https://doi.org/10.1063/1.555739.

Eldred, P. Hough, K. Hu, J. Jakeman, L. Swiler, D. Vigil, DAKOTA, A Multilevel Parallel Object-Oriented Framework for Design Optimization, Parameter Estimation, Uncertainty Quantification, and Sensitivity Analysis: Version 5.4 User's Manual, Sandia Technical Report SAND2010-2183 (2009). B. A. Wols, C. H. M. Hofman-Caris, D. J. H. Harmsen, E. F. Beerendonk, Degradation of 40 selected pharmaceuticals by $\mathrm{UV} / \mathrm{H}_{2} \mathrm{O}_{2}$, Water Res. 47 (2013) 5876-5888. https://doi.org/10.1016/j.watres.2013.07.008. J. R. Bolton, K. G. Bircher, W. Tumas, C. A. Tolman, Figures-of-merit for the technical development and application of advanced oxidation technologies for both electric- and solar-driven systems, Pure Appl. Chem. 73 (2001) 627-637. https://doi.org/10.1351/pac200173040627. J. Rodríguez-Chueca, S. V. Della Giustina, J. Rocha, T. Fernandes, C. Pablos, Á. Encinas, D. Barceló, S. Rodríguez-Mozaz, C. M. Manaia, J. Marugán, Assessment of full-scale tertiary wastewater treatment by UV-C based-AOPs: Removal or persistence of antibiotics and antibiotic resistance genes?, Sci. Total Environ. 652 (2019) 1051-1061. https://doi.org/10.1016/j.scitotenv.2018.10.223. 